\title{
Effects of Ursodeoxycholic Acid on the Biodistribution and Excretion of Various Technetium-99m Radiopharmaceuticals in Rat
}

\section{Yeon-Hee Han ( $\nabla$ yani0878@hanmail.net )}

Chonbuk National University Medical School and Hospital https://orcid.org/0000-0002-7473-2699

Hwan-Jeong Jeong

Jeonbuk National University Medical School and Hospital

Eun-Mi Kim

Jeonbuk National University Hospital

\section{Fatima Boud}

Jeonbuk National University Medical School

\section{Seok Tae Lim}

Jeonbuk National University Medical School and Hospital

Myung-Hee Sohn

Jeonbuk National University Medical School and Hospital

\section{Original research}

Keywords: technetium-99m, ursodeoxycholic acid, radioactivity, renal excretion

Posted Date: November 13th, 2020

DOl: https://doi.org/10.21203/rs.3.rs-104416/v1

License: (9) (i) This work is licensed under a Creative Commons Attribution 4.0 International License. Read Full License 


\section{Abstract \\ Background}

In previous studies, ursodeoxycholic acid (UDCA) accelerated the biliary excretion of technetium-99m (Tc$99 \mathrm{~m}$ ) hepatobiliary radiopharmaceutical and increased F-18 fluoro-deoxy-glucose (FDG) excretion from various organs. As an extension of the previous studies, the present study investigated the effect of oral administration of UDCA on the biodistribution and excretion of various Tc-99m labeled radiopharmaceuticals.

\section{Materials}

Sixty rats were randomly assigned to the Control or UDCA groups. Tc-99m HDP, Tc-99m pertechnetate, and Tc-99m DMSA were injected via the tail vein. Thirty min after the injection, the Control group was administered normal saline and the UDCA group was given $5 \mathrm{mg}$ or $10 \mathrm{mg}$ of UDCA orally. Thirty min, and $1,2,3$, and $4 \mathrm{~h}$ after administration of saline or UDCA, images were acquired using a gamma camera. Images were analyzed by drawing a region of interest (ROI) in the relevant organs depending on the type of radiopharmaceutical used. Four imaging parameters, Radioactivity, Rate of change (\%), Rate of change by section (\%), and Radioactivity/net injection dose (Radioactivity/ID (\%)) were compared between groups. To investigate the action of UDCA on radiotracer excretion in the kidneys and from the soft tissues, Tc-99m $\mathrm{MAG}_{3}$ dynamic imaging was performed and Radioactivity and Radioactivity/total body activity (Radioactivity/TBA (\%)) of the soft tissue, both kidneys, and the bladder were compared.

\section{Results}

In the image analysis of Tc-99m HDP with $10 \mathrm{mg}$ of UDCA, Radioactivity, and Radioactivity/ID (\%) of the buttock was lower in the UDCA group at $4 \mathrm{~h}(P=0.019, P=0.031)$. Similar effects were also found in the Tc-99m HDP experiments with $5 \mathrm{mg}$ of UDCA. Rate of change (\%) of buttock Radioactivity was significantly different at $3 \mathrm{~h}-30 \mathrm{~min}$ and $4 \mathrm{~h}-30$ min and buttock Radioactivity in the UDCA group decreased more substantially $(P=0.008, P=0.024)$. In the image analysis of Tc-99m pertechnetate, Radioactivity of the buttock was higher in the Control group at 1, 3, and $4 \mathrm{~h}$. Rates of change (\%) in the thyroid gland and the buttock were different at $1 \mathrm{~h}-30 \mathrm{~min}, 3 \mathrm{~h}-30 \mathrm{~min}$, and $4 \mathrm{~h}-30 \mathrm{~min}$ and Radioactivity in the UDCA group decreased more substantially. Radioactivity/ID (\%) was statistically different in the buttock at $4 \mathrm{~h}(P=0.041)$. In the image analysis of Tc-99m DMSA, Radioactivity of the kidney increased in the UDCA group at $1 \mathrm{~h}-30 \mathrm{~min}$, while that in the Control group showed little change. In the analysis of the Tc-99m MAG 3 dynamic images, Radioactivity and Radioactivity/TBA (\%) of the kidney were significantly higher in the UDCA group at $2 \min (P=0.014, P=0.035)$. At 5 and $10 \mathrm{~min}$, Radioactivity/TBA (\%) of the soft tissue in the UDCA group was lower than that of the Control group $(P=$ 
$0.001, P=0.022)$. At 20,25 , and 30 min, there was no difference in Radioactivity and Radioactivity/TBA (\%) of soft tissue, both kidneys, and the bladder.

\section{Conclusion}

The present study demonstrated that administration of UDCA increases renal excretion and soft tissue clearance of Tc-99m labeled radiopharmaceuticals. This investigation could contribute to broadening of the field of pharmacologic application of UDCA.

\section{Background}

Technetium-99m (Tc-99m) scintigraphy is widely-used less-invasive imaging modality that has been used to evaluate the functions of various organs and diagnose diseases. Tc-99m diphosphonate bone scintigraphy is one of the most commonly used imaging tests in the nuclear medicine department to survey bone metastasis or to characterize various bone lesions. Tc-99m pertechnetate scintigraphy is also widely performed to evaluate thyroid and salivary gland function and to detect ectopic gastric mucosa in Meckel's diverticulum. Tc-99m dimercaptosuccinic acid (DMSA) scintigraphy, which is very sensitive for detecting renal cortical abnormalities, is often used to detect pyelonephritis in patients suspected of urinary tract infection.

Ursodeoxycholic acid (UDCA), the 7- $\beta$ hydroxy epimer of chenodeoxycholic acid (Fig. 1), is normally present in humans in a concentration of about $3 \%$ of the bile acid pool [1] and has various hepatoprotective effects that involve increasing the hydrophilicity of bile juice. It modifies the bile acid component by decreasing the levels of hydrophobic bile acids while increasing the proportion of nontoxic hydrophilic bile acids. It also has a choleretic effect, facilitating hepatocellular bile acid excretion, as well as having cytoprotective, membrane stabilizing, and immunomodulatory properties [2-4]. UDCA is a Food and Drug Administration-approved medicine for cholesterol gall stone dissolution and primary biliary cirrhosis [5]. Although UDCA was evaluated as an investigational medicine in a wide swath of hepatic and extrahepatic disorders, studies applying UDCA to the molecular imaging field are rare.

In a previous clinical study with young, healthy volunteers (mean age: $26.3 \pm 2.1$ years), hepatobiliary scintigraphy was performed twice per volunteer within three days, for the control and the UDCA-treated studies [6]. When the subjects were orally administered a single dose of UDCA (200 mg) $15 \mathrm{~min}$ before intravenous injection of Tc-99m diisopropyliminodiacetic acid (DISIDA), the time until visualization of the gallbladder (GB) was shortened from $14.2 \pm 6.6$ to $9.1 \pm 2.8 \mathrm{~min}$, and the maximum activity of the GB was markedly increased from $83.8 \pm 38.4$ to $132.3 \pm 59.8$ [6]. With UDCA pretreatment, the GB was clearly visualized in an earlier phase of hepatobiliary scintigraphy. Consequently, UDCA shortened the total imaging time and increased the specificity of hepatobiliary scintigraphy for assessing functional obstruction of the cystic duct. 
Furthermore, based on a report that UDCA increases lipase activity, which breaks down triglycerides [7], we investigated the effects of oral administration of milk and UDCA on the excretion of 2-deoxy-2$\left[{ }^{18}\right.$ F]fluoro-d-glucose (F-18 FDG) from various organs of rats [8]. Administration of milk and UDCA enhanced F-18 FDG efflux from the brain, liver, and small intestine. There was a significant increase in

glucose-6-phosphatase (G6Pase) and a decrease in hexokinase 2 (HK2) expression in the organs in the milk + UDCA group compared to those of the Control group [8]. This suggested that F-18 FDG-6phosphate was dephosphorylated by G6Pase and transformed into F-18 FDG which is a chemical structure that is easily effluxed from cells. In addition, decreased HK2 expression was also considered to contribute to the back diffusion of F-18 FDG from the organs. Since HK2 phosphorylated F-18 FDG to F18 FDG-6-phosphate, which is retained in the cytoplasm and hardly diffuses from cells, decreased HK2 expression was thought to increase the portion of F-18 FDG compared to F-18 FDG-6-phosphate, resulting in reduced radioactivity of the organs.

As an extension of the previous studies, the current study aimed to investigate the effect of oral administration of UDCA on the biodistribution and excretion of three Tc-99m labeled radiopharmaceuticals, Tc-99m hydroxy-methylene-diphosphonate (HDP), Tc-99m pertechnetate, and Tc$99 \mathrm{~m}$ DMSA, in rats. Furthermore, this study tried to identify possible mechanisms underpinning the phenomenon with a Tc-99m mercapto-acetyl-triglycine $\left(\mathrm{MAG}_{3}\right)$ experiment.

\section{Materials And Methods}

Animals and materials

Female Sprague-Dawley rats (aged 8-9 weeks old, weighing 190-210 g) were purchased from Orient-Bio Inc. (Seongnam, Korea). Ursodeoxycholic acid (UDCA, $200 \mathrm{mg}$ per tablet) was purchased from Daewoong Pharmaceutical Co. Ltd. (Seoul, Korea). HDP, pertechnetate, DMSA, and $\mathrm{MAG}_{3}$ were purchased from New Korea Industrial (Seoul, Korea) and labeled with Tc-99m according to the provided procedure. All protocols involving animals were conducted in compliance with the policies and procedures of the Institutional Animal Care and Use Committee of Jeonbuk National University (CBNU 2019 - 108).

\section{Experimental protocols}

Sixty rats were randomly assigned to the Control or UDCA groups. About $300 \mu \mathrm{L}(74 \mathrm{MBq}, 2 \mathrm{mCi})$ of Tc99m HDP, Tc-99m pertechnetate, or Tc-99m DMSA were injected via tail vein of the rats under anesthesia by inhalation of isoflurane (2\%). Injection time, dose of the radiotracer prepared, and the dose that remained in the syringe after injection were recorded to calculate the net injection dose.

Just after radiotracer injection, total body radioactivities of the rat were measured by placing the rat into a well-type dose calibrator (Capintec Inc., USA, 2012. Figure 2a). UDCA was prepared by grinding the tablets into a fine powder using a mortar and pestle and dissolving the powder in normal saline. Thirty min after radiotracer injection, the Control group was administered normal saline $(500 \mu \mathrm{L}, 0.9 \%)$ and the UDCA group was given $5 \mathrm{mg}$ or $10 \mathrm{mg}$ of UDCA $(500 \mu \mathrm{L})$ orally using a flexible oral zonde needle $(\Phi 1.7 \times$ 
$90 \mathrm{~mm}$, polyethylene tube, Duksan General Science, Seoul, Korea, Fig. 2b). The amounts of UDCA were calculated based on the practice guide for dose conversion between animals and humans and previous experiments $[8,9]$.

At each time points (30 min and, 1, 2, 3, and $4 \mathrm{~h}$ ) after administration of normal saline or UDCA, images were sequentially acquired for 2 min using a gamma camera (Symbia T16, Siemens Medical Solutions, USA, 2011) with an energy peak setting of $140 \mathrm{keV} \pm 7.5 \%$ for Tc-99m. One detector with a low-energy high-resolution collimator was used with at a distance of $7 \mathrm{~cm}$ between the detector and the table. During image acquisition, a standard point source of radioactivity of about $1.11 \mathrm{MBq}(30 \mu \mathrm{Ci})$ of the same radiopharmaceutical in $1 \mathrm{~mL}$ of normal saline was placed at the upper left corner of the image field for image analysis. After all 5 time points, total body activity of the rat was measured once again using a dose calibrator.

Image analysis

Images were analyzed using PMOD software (version 3.7) by drawing a region of interest (ROI) over the relevant organs depending on the type of radiotracer used. For analysis of the Tc-99m HDP image, the right shoulder, lumbar spine, liver, and right buttock were chosen. The ROI over the right shoulder was a $10.0 \times 10.0 \mathrm{~mm}$ circle, while that over the lumbar spine was an $8.0 \times 16.0 \mathrm{~mm}$ rectangle. Those over the liver, and right buttock were $12.0 \times 12.0 \mathrm{~mm}$ circles (Fig. 3a). For analysis of the Tc-99m pertechnetate image, ROls were drawn over the thyroid gland, stomach, and right buttock. The ROI over the thyroid gland was a $13.0 \times 13.0 \mathrm{~mm}$ circle. That over the stomach was a $30.0 \times 25.0 \mathrm{~mm}$ oval and that over the right buttock was a $15.0 \times 15.0 \mathrm{~mm}$ circle (Fig. 3b). For analysis of the Tc-99m DMSA image, ROls were drawn over the right kidney, left kidney, and right buttock. The ROI over each kidney was a $22.0 \times 29.0 \mathrm{~mm}$ oval and that over the buttock was a $15.0 \times 15.0 \mathrm{~mm}$ circle (Fig. 3c). The ROI over the standard point source was drawn as a $27.2 \times 52.4 \mathrm{~mm}$ rectangle in all radiotracer images.

Four imaging parameters, Radioactivity, Rate of change (\%), Rate of change by section (\%),

Radioactivity/time-corrected net injection dose (Radioactivity/ID (\%)), were compared. The first parameter, Radioactivity $(\mathrm{kBq})$ was calculated from counts in the ROI using a correction factor deduced from standard point source information. The second parameter, Rate of change (\%) was calculated as (radioactivity at each time point - radioactivity of $30 \mathrm{~min}$ image)/radioactivity of $30 \mathrm{~min}$ image, which reflects the rate of change from time $30 \mathrm{~min}$ to each specific time point. The third parameter, Rate of change by section (\%), was calculated as (radioactivity at each time point - radioactivity at the time point just before)/radioactivity of the time point just before. The last parameter, Radioactivity/time-corrected net injection dose (Radioactivity/ID (\%)), was calculated by dividing Radioactivity of the ROI by timecorrected net injection dose.

Tc-99m $\mathrm{MAG}_{3}$ experiment

Tc-99m $\mathrm{MAG}_{3}$ was used to elucidate the mechanism of action of UDCA on radiotracer excretion in the kidneys and from the soft tissues using dynamic image acquisition. Thirteen rats were randomly 
distributed to the Control $(n=6)$ and UDCA $(n=7)$ groups.

Images were obtained 10 min after oral administration of normal saline (500 $\mu \mathrm{L}$, Control group) or UDCA (500 $\mu \mathrm{L}, 10 \mathrm{mg}$, UDCA group). Before acquiring the scans, rats were anesthetized and a 27-gauge infusion set with a $30 \mathrm{~cm}$ tube filled with saline supplemented with heparin (50 international units (IU)/mL) was inserted into a tail vein [10]. Just after the start of the dynamic image acquisition, about $300 \mu \mathrm{L}$ (74 MBq) of Tc-99m MAG 3 was infused, followed by flushing with $700 \mu \mathrm{L}$ of normal saline. Dynamic images were acquired for $30 \mathrm{~min}$ at a rate of 1 frame per second, resulting in a total of 1800 scans.

Images were analyzed by drawing ROls over the total body, both kidneys, and the bladder. The ROI of the total body was $110.7 \times 211.2 \mathrm{~mm}$ and that of the standard point source was a $27.2 \times 52.4 \mathrm{~mm}$ rectangle. The ROls over both kidneys and the bladder were drawn along the outlines of the organs (Fig. 3d).

Soft tissue radioactivity was calculated by subtracting the radioactivity of both kidneys and the bladder from total body radioactivity. Since there might be functional differences between the left and right kidneys, the sum of both kidneys' counts was used for image analysis and for calculating the time to peak renal activity $\left(T_{\text {max }}\right)$ and half-time of renal activity $\left(T_{1 / 2}\right)$. Radioactivity and Radioactivity/total body activity (radioactivity/TBA (\%)) of the soft tissue, both kidneys, and the bladder were compared.

\section{Statistical analysis}

All data are presented as mean \pm standard deviation (SD). All image parameters and total body activity of both groups were compared using the Mann-Whitney U test (IBM, SPSS Statistics 23 USA). A $P$ value of less than 0.05 was considered statistically significant.

\section{Results}

Tc-99m HDP image interpretation

In the image analysis of Tc-99m HDP $(n=18)$ with 10 mg of UDCA, buttock Radioactivity and Radioactivity/ID (\%) were lower in the UDCA group at the $4 \mathrm{~h}$ time point (buttock, Radioactivity, Control : UDCA $=19.943 \pm 1.542 \mathrm{kBq}: 15.207 \pm 2.035 \mathrm{kBq}, P=0.019$, Fig. 4a, Radioactivity/ID, Control : UDCA = $0.050 \pm 0.010 \%: 0.039 \pm 0.007 \%, P=0.031$, Fig. $4 \mathrm{~b})$. Rate of change (\%) of liver activity was different at $2 \mathrm{~h}-30$ min and $4 \mathrm{~h}-30$ min and liver activity in the UDCA group decreased more substantially (liver, Rate of change at $2 \mathrm{~h}-30 \mathrm{~min}$, Control : UDCA $=-31.083 \pm 2.181 \%:-34.525 \pm 2.627 \%, P=0.011$, Rate of change at $4 \mathrm{~h}-30 \mathrm{~min}$, Control : UDCA $=-46.010 \pm 3.402 \%:-50.761 \pm 4.314 \%, P=0.024$, Fig. $4 \mathrm{c})$. There was a statistically significant difference in Rate of change by section (\%) at $2 \mathrm{~h}-1 \mathrm{~h}$ in the liver and buttock (buttock, Rate of change by section at $2 \mathrm{~h}-1 \mathrm{~h}$, Control : UDCA $=-5.679 \pm 4.770 \%:-22.857 \pm$ $8.471 \%, P=0.040)$.

Similar effects were found in the Tc-99m HDP experiment with $5 \mathrm{mg}$ of UDCA $(\mathrm{n}=18)$. The Rate of change (\%) of buttock radioactivity was significantly different between the 2 groups at $3 \mathrm{~h}-30$ min and 
$4 \mathrm{~h}-30$ min and the buttock showed a greater decrease in radioactivity in the UDCA group (buttock, Rate of change at $3 \mathrm{~h}-30 \mathrm{~min}$, Control : UDCA $=-47.468 \pm 7.073 \%:-57.312 \pm 5.729 \%, P=0.008$, Rate of change at $4 \mathrm{~h}-30 \mathrm{~min}$, Control : UDCA $=-56.195 \pm 4.881 \%:-64.825 \pm 7.452 \%, P=0.024$, Fig. $4 \mathrm{~d})$. Use of $10 \mathrm{mg}$ of UDCA was not associated with greater radioactivity excretion from soft tissue compared to $5 \mathrm{mg}$ of UDCA. The 4 imaging parameters of ROls in the lumbar spine and the right shoulder were not significantly different between the 2 groups in either the $5 \mathrm{mg}$ or $10 \mathrm{mg}$ of UDCA experiments.

Tc-99m pertechnetate image interpretation

In the image analysis of Tc-99m pertechnetate $(n=12)$, Radioactivity of the buttock was greater in the Control group at 1, 3, and $4 \mathrm{~h}$ (buttock, Radioactivity at $1 \mathrm{~h}$, Control : UDCA $=404.225 \pm 22.393 \mathrm{kBq}$ : $316.572 \pm 8.279 \mathrm{kBq}, P=0.026$, Radioactivity at $3 \mathrm{~h}$, Control : UDCA $=230.214 \pm 13.232 \mathrm{kBq}: 187.146 \pm$ $5.079 \mathrm{kBq}, P=0.009$, Radioactivity at $4 \mathrm{~h}$, Control : UDCA $=197.654 \pm 13.032 \mathrm{kBq}: 138.158 \pm 23.372 \mathrm{kBq}$, $P=0.015$, Fig. 5a). The Rates of change (\%) in the buttock also differed at $1 \mathrm{~h}-30 \mathrm{~min}, 3 \mathrm{~h}-30 \mathrm{~min}$, and $4 \mathrm{~h}-30 \mathrm{~min}$ and activity in the UDCA group decreased more substantially (buttock, Rate of change at $1 \mathrm{~h}-30 \mathrm{~min}$, Control : UDCA $=-14.992 \pm 4.912 \%:-32.191 \pm 3.880 \%, P=0.004$, Rate of change at $3 \mathrm{~h}-$ $30 \mathrm{~min}$, Control : UDCA $=-51.392 \pm 5.152 \%:-60.041 \pm 4.455 \%, P=0.015$, Rate of change at $4 \mathrm{~h}-30 \mathrm{~min}$, Control : UDCA $=-58.177 \pm 3.024 \%:-70.230 \pm 2.866 \%, P=0.009$, Fig. $5 \mathrm{~b}$ ). Rate of change by section (\%) significantly differed at $1 \mathrm{~h}-30 \mathrm{~min}$ in the buttock. Radioactivity/ID (\%) in the buttock was lower in the UDCA group at $4 \mathrm{~h}$ (buttock, Radioactivity/ID at $4 \mathrm{~h}$, Control : UDCA $=0.409 \pm 0.033 \%: 0.305 \pm 0.024 \%, P=$ 0.041 , Fig. 5c).

Rate of change (\%) in the thyroid gland was different at $1 \mathrm{~h}-30 \mathrm{~min}$ and $4 \mathrm{~h}-30 \mathrm{~min}$ and radioactivity decreased more substantially in the UDCA group (thyroid gland, Rate of change at $1 \mathrm{~h}-30 \mathrm{~min}$, Control : UDCA $=-20.558 \pm 4.958 \%:-28.698 \pm 2.536 \%, P$-value $=0.041$, Rate of change at $4 \mathrm{~h}-30$ min, Control : UDCA $=-64.947 \pm 2.860 \%:-71.165 \pm 4.181 \%, P=0.026$, Fig. $5 d$ ). Radioactivity/ID (\%) in the thyroid gland at $30 \mathrm{~min}$ also significantly differed (thyroid gland, Radioactivity/ID at $30 \mathrm{~min}$, Control : UDCA $=1.064 \pm$ $0.044 \%: 1.285 \pm 0.098 \%, P=0.041$ ), such that Radioactivity/ID (\%) of the UDCA group was higher at the early time point of $30 \mathrm{~min}$.

The 4 imaging parameters showed no differences between the Control and the UDCA groups in the stomach ROI.

Tc-99m DMSA image interpretation

In the image analysis of Tc-99m DMSA $(n=12)$, while the Radioactivity of the kidney in the Control group showed little decrease at $1 \mathrm{~h}-30 \mathrm{~min}$, that in the UDCA group increased (kidney, Rate of change at $1 \mathrm{~h}-$ 30 min, Control : UDCA $=-0.787 \pm 0.531 \%: 4.335 \pm 1.144 \%, P=0.002$, Fig. 6$)$. These findings suggest accumulation of radiotracer into the kidneys in the UDCA group earlier in the experiment. Radioactivity of the buttock decreased more in the UDCA group at $3 \mathrm{~h}-30$ min (buttock, Rate of change at $3 \mathrm{~h}-30 \mathrm{~min}$, Control : UDCA $=-32.456 \pm 2.826 \%:-43.164 \pm 3.470 \%, P=0.065)$. 
Net injection dose and total body radioactivity measured by dose calibrator

Net injection dose (Net ID) was calculated by subtracting the radioactivity that remained in the syringe after injection from the radioactivity of the radiotracer as prepared. Time correction was applied based on the injection time to calculate the net injection dose. Net ID was not statistically different between the Control and the UDCA groups in all radiopharmaceutical experiements (Table 1). Total body radioactivity (TBA) measured just after radiotracer injection was similar between the Control and the UDCA groups in all experiments. The TBAs after all 5 image acquisition time points were generally lower in the UDCA group, except in the Tc-99m DMSA experiment. However, there were no significant differences between the 2 groups (Fig. 7 and Table 1).

Table 1

Net injection dose (Net ID) and total body radioactivity (TBA) measured by dose calibrator after image acquisition

\begin{tabular}{|lllll|}
\hline & Group & $\begin{array}{l}\text { UDCA dose } \\
(\mathbf{m g})\end{array}$ & $\begin{array}{l}\text { Net ID* } \\
\mathbf{( k B q})\end{array}$ & $\begin{array}{l}\text { TBAt } \\
\mathbf{( k B q )}\end{array}$ \\
\hline \multirow{2}{*}{ Tc-99m HDP } & Control & 0 & $75.887 \pm 4.366$ & $23.754 \pm 3.441$ \\
\cline { 2 - 5 } & UDCA & 5 & $75.500 \pm 6.142$ & $21.238 \pm 2.516$ \\
\hline Tc-99m HDP & Control & 0 & $68.672 \pm 7.289$ & $19.573 \pm 4.958$ \\
\cline { 2 - 5 } & UDCA & 10 & $68.833 \pm 7.067$ & $19.129 \pm 3.885$ \\
\hline Tc-99m & Control & 0 & $74.958 \pm 5.772$ & $32.227 \pm 3.709$ \\
\cline { 2 - 5 } pertechnetate & UDCA & 10 & $74.178 \pm 5.180$ & $29.822 \pm 3.848$ \\
\hline Tc-99m DMSA & Control & 0 & $64.010 \pm 6.586$ & $34.780 \pm 3.922$ \\
\cline { 2 - 5 } & UDCA & 10 & $65.305 \pm 5.883$ & $35.076 \pm 4.070$ \\
\hline * ID : injection dose & & & \\
† TBA : total body radioactivity & & \\
\hline
\end{tabular}

Tc-99m $\mathrm{MAG}_{3}$ image interpretation

Time-activity curves of radioactivity in the kidneys in the 2 groups were drawn and compared. Because renal function may differ between the 2 kidneys in the same animals, whole-kidney radioactivity was used to draw the time-activity curve. Time to peak renal activity $\left(T_{\max }\right)$ and half-time of renal activity $\left(T_{1 / 2}\right)$ were shorter in the UDCA group $\left(T_{\max }=3.430 \mathrm{~min} ; T_{1 / 2}=17.432 \mathrm{~min}\right)$ than in the Control group $\left(T_{\max }=4.134 \mathrm{~min} ; T_{1 / 2}=23.321 \mathrm{~min}\right.$ ). $T_{\max }$ and $T_{1 / 2}$ are shown on the kidney time-activity curve (Fig. 8).

Radioactivity and Radioactivity/TBA (\%) of soft tissue, both kidneys, and the bladder were compared at the time points of $2,5,10,15,20,25$, and $30 \mathrm{~min}$. 
At 2 min, Radioactivity and Radioactivity/TBA (\%) of the kidney were greater in the UDCA group than in the Control group, which suggested early accumulation of Tc-99m MAG 3 in the kidneys in the UDCA group similar to Tc-99m DMSA experiment (Tc-99m MAG 3 kidney Radioactivity, Control : UDCA = $16.361 \pm$ $1.456 \mathrm{MBq}: 19.000 \pm 1.477 \mathrm{MBq}, P=0.014)$, (kidney Radioactivity/TBA(\%), Control : UDCA = 33.639 \pm $3.000 \%: 36.882 \pm 1.515 \%, P=0.035)$.

At the 5 and 10 min time points, Radioactivity/TBA (\%) of the soft tissue in the UDCA group was lower than that of the Control group ( $5 \mathrm{~min}$, Control : UDCA $=52.907 \pm 3.292 \%: 48.215 \pm 1.063 \%, P$-value $=$ 0.001), (10 min, Control : UDCA $=40.051 \pm 4.344 \%: 36.066 \pm 2.529 \%, P=0.022)$.

At the 15 min time point, Radioactivity/TBA (\%) of the soft tissue in the Control group was higher than that of the UDCA group, however, the $P$-value was 0.051 (15 min, Control : UDCA $=32.793 \pm 3.986 \%$ : $29.532 \pm 2.793 \%, P=0.051)$.

At the 20,25, and 30 min time points, there was no difference between the 2 groups in Radioactivity and Radioactivity/TBA of soft tissue, both kidneys, and the bladder. Figure 9 demonstrates Radioactivity/TBA $(\%)$ curves of the soft tissue and bladder. An asterisk (*) indicates statistical significance.

Net ID and peak radioactivity of the kidney did not differ between the 2 groups (net ID, Control : UDCA = $51.282 \pm 1.998 \mathrm{MBq}: 52.392 \pm 1.110 \mathrm{MBq}$, peak radioactivity of the kidney, Control : UDCA $=19.729 \pm$ 3.279 MBq: $22.036 \pm 3.008 \mathrm{MBq})$.

\section{Discussion}

UDCA, 3a,7 $\beta$-dihydroxy-5 $\beta$-cholan-24-oic acid, is normally present in the human bile acid pool at concentration up to $4 \%$; it is formed by $7 \beta$-epimerization of chenodeoxycholic acid in the colon by a bacterial enzymatic reaction [10]. UDCA is the only drug approved by the Food and Drug Administration for treatment of primary biliary cirrhosis. It is also approved for cholesterol gall stone dissolution. UDCA reportedly increases the hydrophilicity of the bile acid pool and bile flow as well as exerting immunesuppressive effects [11-13].

After oral administration of UDCA, about $90 \%$ of a therapeutic dose is absorbed in the small bowel and enters the portal circulation [14]. Subsequently, it undergoes efficient extraction from portal blood by the liver. First-pass extraction from the portal blood ranges from 50-70\% [15]. In the liver, UDCA is conjugated with either glycine or taurine and excreted into the bile [15]. UDCA in bile juice accumulates in the gallbladder and is expelled into the duodenum. In the small intestine, some conjugated UDCA is deconjugated and reabsorbed in the terminal ileum [15]. Small quantities of UDCA appear in the systemic circulation due to its high first-pass metabolism [16].

The biologic half-life of orally administered UDCA in humans is quite long, estimated at 3.5 to 5.8 days, due to enterohepatic circulation [15]. After oral administration of a $500 \mathrm{mg}$ tablet of UDCA to healthy volunteers, $T_{\max }$ of plasma concentrations occurs at $60 \mathrm{~min}$ and a second peak concentration occurs at 
$180 \mathrm{~min}$ [15]. In the present study, most Tc-99m radiopharmaceuticals remaining in the soft tissue were observed to be significantly lower in the UDCA group at the 3 and $4 \mathrm{~h}$ time points. The long time course of UDCA action is considered due to be its long biologic half-life related to effective enterohepatic circulation.

UDCA is known to act mainly in the hepatobiliary system. In the current study, I measured liver Radioactivity with Tc-99m HDP, and as expected, liver Radioactivity in the UDCA group showed greater excretion than was seen in the Control group at the $2 \mathrm{~h}-30 \mathrm{~min}$ and $4 \mathrm{~h}-30 \mathrm{~min}$.

UDCA is generally well tolerated with few side effects. Diarrhea is the main reported side effect. The incidence of diarrhea in controlled human studies was up to $3 \%$ [15]. In the current study, only a few rats showed loose stool after taking UDCA and no rat suffered from watery diarrhea.

During clinical imaging tests, various pharmacologic interventions have been attempted to aid diagnosis. In the nuclear medicine field, when performing scintigraphy for Meckel's diverticulum, glucagon can be used to increase the intake of Tc-99m pertechnetate, and cimetidine can be administered to suppress excretion from the gastric mucosa, with the aim of reaching a higher lesion-to-background ratio with high sensitivity. When performing a hepatobiliary scan to check for acute cholecystitis, if the gallbladder does not show for up to $1 \mathrm{~h}$, instead of obtaining a delayed image at $4 \mathrm{~h}$, morphine can be administered to increase biliary tract pressure by contracting the sphincter of Oddi.

The mechanisms of uptake and excretion pathways of various radiopharmaceuticals are thought to be one factor affecting the action of UDCA. Tc-99m HDP, one type of Tc-99m diphosphonate radiopharmaceutical, is taken up by hydroxyapatite crystals in the surface of bone by chemisorption. This strong adsorption may make it difficult for UDCA to release Tc-99m HDP from the bones and joints. In the experiments with Tc-99m HDP in the normal rat and fracture model, the 4 imaging parameters of ROls in the lumbar spine and the shoulder were not significantly different between the 2 groups. On the other hand, on day \#1 after fracture, the amount of Radioactivity at the tibia fracture site decreased more in the UDCA group at $2 \mathrm{~h}-30 \mathrm{~min}, 3 \mathrm{~h}-30 \mathrm{~min}$, and $4 \mathrm{~h}-30 \mathrm{~min}$. It is presumed that UDCA can act more freely in tissue that has been loosened by a fracture. This effect of UDCA was not seen at the tibia fracture site on day \#6 after fracture. Unlike Radioactivity of the fracture site, that of the buttock, representing soft tissue, was found to be lower in the UDCA group in both normal rats and fracture models mostly at the 3 or $4 \mathrm{~h}$ time points.

Tc-99m pertechnetate scintigraphy is a widely performed nuclear imaging modality that is used to evaluate thyroid and salivary gland function and to detect ectopic gastric mucosa in Meckel's diverticulum. Tc-99m pertechnetate is transported by the sodium iodide symporter; therefore, Tc-99m pertechnetate scintigraphy is a powerful imaging modality for assessing sodium iodide symporter activity in various organs $[16,17]$.

Tc-99m DMSA scintigraphy is used to gain information on renal cortical morphology. Two mechanisms of Tc-99m DMSA tubular uptake are peritubular extraction from the blood into the proximal tubular cell of 
the pars recta, where the last straight part of the proximal tubule and glomerular filtration, followed by tubular reabsorption [18-21].

Tc-99m $\mathrm{MAG}_{3}$, another popular renal radiopharmaceutical, is more specific to renal excretory function. The most important mechanism of uptake of Tc- $99 \mathrm{~m} \mathrm{MAG}_{3}$ is extraction from blood in efferent arterioles by basolateral uptake into cells lining the proximal tubules, which mediated by an active anion transport system and mostly occurs in the first convoluted portion of the proximal tubules [22]. Various factors can affect the absorption and excretion of radiopharmaceuticals, such as the patient's clinical condition, the radiopharmaceutical preparation method, and the effects of other medicines which the patient is taking. Given the results of the current study, UDCA is thought to be an example of a medicine that affects uptake and excretion of various radiopharmaceuticals. The locations of UDCA's impact and the substances on which UDCA acts should be identified at the cellular and molecular biological level in further studies.

TBA measured by a dose calibrator after image acquisition was also generally lower in the UDCA group, except for in the Tc-99m DMSA experiment. $T_{\max }$ and $T_{1 / 2}$ obtained in the Tc-99m $M_{A} G_{3}$ experiment were also shorter in the UDCA group ( $\left.T_{\max }: 3.430 \mathrm{~min}, T_{1 / 2}: 17.432 \mathrm{~min}\right)$ than in the Control group $\left(T_{\max }\right.$ : $\left.4.134 \mathrm{~min}, T_{1 / 2}: 23.321 \mathrm{~min}\right)$. However, the differences were not statistically significant. The reason for statistical insignificance might be the small number of rats used. A further larger-scale experiment is necessary.

This study has several limitations. First, since investigating the effect of UDCA on various radiopharmaceuticals, the number of rats in each radiopharmaceutical group was not large. Second, the dose-effect of UDCA was confirmed only in the Tc-99m HDP experiment using 5 and $10 \mathrm{mg}$ of UDCA. Studies with more varied doses should be conducted to determine the optimal dose. Third, in the renal excretion experiment using Tc-99m MAG 3 , because the time that rats could be maintained under anesthesia was limited to 30 min due to safety concerns, the pharmacological effects of UDCA after 30 min could not be investigated. Besides, because this study confirmed the effects of UDCA only by animal experiments using rats, additional research at the cellular and molecular biological scale is necessary to identify the mechanisms of action of UDCA on various Tc-99m radiopharmaceuticals. Nevertheless, to our knowledge, it is the first study to evaluate the effect of UDCA on the biodistribution and renal excretion of various Tc-99m radiopharmaceuticals.

\section{Conclusions}

In sum, various parameters in the buttock of the UDCA group were lower in all 3 Tc-99m radiopharmaceutical experiments. Liver activity in the Tc-99m HDP experiment and thyroid activity in the Tc-99m pertechnetate experiment were also lower in the UDCA group than the Control group. However, UDCA did not affect any of the 4 parameters in the lumbar spine or shoulder joint. Interestingly, in the Tc$99 \mathrm{~m}$ DMSA experiment, earlier accumulation of the radiotracer into the kidneys was found in the UDCA 
group. The results of the Tc-99m $\mathrm{MAG}_{3}$ dynamic study suggested that UDCA accelerated urinary excretion of Tc-99m radiopharmaceuticals and decreased the background activity of soft tissue.

In conclusion, the present study demonstrates that administration of UDCA increases renal excretion and soft tissue clearance of certain Tc-99m labeled radiopharmaceuticals. This investigation could contribute to broadening the field of pharmacologic application of UDCA.

\section{Abbreviations}

DISIDA: diisopropyliminodiacetic acid

DMSA: dimercaptosuccinic acid

F-18 FDG: 2-deoxy-2-[ $\left[{ }^{18}\right.$ F]fluoro-d-glucose

GB: gallbladder

G6Pase: glucose-6-phosphatase

h: hour

HDP: hydroxy-methylene-diphosphonate

HK2: hexokinase 2

ID: injection dose

IU: international unit

kBq: kilobecquerel

$\mathrm{MAG}_{3}$ : mercapto-acetyl-triglycine

mCi: millicurie

min: minutes

ROI: region of interest

SD: standard deviation

TBA: total body activity

Tc-99m: technetium-99m

$T_{\text {max }}$ : time to peak renal activity 
$\mathrm{T}_{1 / 2}$ : half-time of renal activity

UDCA: ursodeoxycholic acid

\section{Declarations}

\section{Acknowledgements}

Not applicable.

\section{Funding}

This paper was supported by Fund of Biomedical Research Institute of Jeonbuk National University Hospital.

\section{Author information}

Yeon-Hee Han, Hwan-Jeong Jeong, Eun-Mi Kim, Fatima Boud, Seok Tae Lim, and Myung-Hee Sohn

\section{Affiliation}

Department of NuclearMedicine, Molecular Imaging \& Therapeutic Medicine Research Center, Research Institute of Clinical Medicine of Jeonbuk National University - Biomedical Research Institute of Jeonbuk National University Hospital, Jeonju, Jeonbuk, Republic of Korea

\section{Authors' contributions}

Yeon-Hee Han and Hwan-Jeong Jeong contributed equally to this work. Yeon-Hee Han and Hwan-Jeong Jeong contributed mainly for establishing study design and undertook writing a draft together. Eun-Mi Kim and Fatima Boud contributed to animal experiments. Questions related to the accuracy or integrity of this work were investigated and resolved by Seok Tae Lim and Myung-Hee Sohn. Final approval of the version to be published was done by all authors. All authors also meet the ICMJE Authorship Criteria. They agreed with the designation of two first authors (Yeon-Hee Han and Hwan-Jeong Jeong) and accepted the order of author list.

\section{Corresponding author}

Correspondence to Myung-Hee Sohn.

\section{Ethics declaration}

\section{Ethics approval and consent to participate}

All protocols involving animals were conducted in compliance with the policy and procedure of the Institutional Animal Care and Use Committee of Jeonbuk National University (CBNU 2019-081) and with 
the 1964 Helsinki declaration and its later amendments or comparable ethical standards.

\section{Consent for publication}

Not applicable.

\section{Competing interests}

All authors declare that they have no conflicts of interest.

\section{Availability of data and materials}

All data generated or analyzed during this study are included in this published article.

\section{References}

1. Hofmann AF. Pharmacology of ursodeoxycholic acid, an enterohepatic drug. Scand J Gastroenterol. 1994;204:S1-S15.

2. Angulo P. Use of ursodeoxycholic acid in patients with liver disease. Curr Gastroenterol Rep. 2002;4:37-44.

3. Van de Meeberg PC, van Erpecum KJ, van Berge Henegouwen GP. Therapy with ursodeoxycholic acid in cholestatic liver disease. Scand J Gastroenterol Suppl. 1993;200:15-20.

4. Arrese M, Pizarro M, Solis N, Koenig C, Accatino L. Enhanced biliary excretion of canalicular membrane enzymes in ethynylestradiol-induced cholestasis. Effects of ursodeoxycholic acid administration. Biochem Pharmacol. 1995;50:1223-32.

5. Bowlus CL, Kenney JT, Rice G, Navarro R. Primary biliary cholangitis: medical and specialty pharmacy management update. J Manag Care Spec Pharm. 2016;22(10-a-s Suppl):S3-S15.

6. Jeong HJ, Kim CG. Pretreatment with ursodeoxycholic acid (UDCA) as a novel pharmacological intervention in hepatobiliary scintigraphy. Yonsei Med J. 2005;46:394-8.

7. Alam MS, Teshima S, Ishikawa M, Koshio S, Ohtao H. The role of ursodeoxycholic acid on growth performance and digestive enzyme activities of tilapia oreochromis niloticus and kuruma prawn marsupenaeus japonicus. Asian Fisheries Science Journal. 2001;14:441-51.

8. Jeong HJ, Bagalkot TR, Kim HS, Han YH, Kim M, Lim ST, et al. Radioactivity Reduction of 2-deoxy-2$\left[{ }^{18} \mathrm{~F}\right]$ fluoro-d-glucose by milk and ursodeoxycholic acid in preclinical study. Nucl Med Mol Imaging. 2020;54:105-13.

9. Nair AB, Jacob S. A simple practice guide for dose conversion between animals and human. J Basic Clin Pharm. 2016;7:27-31.

10. Angulo, P. Use of ursodeoxycholic acid in patients with liver disease. Curr. Gastroenterol. Rep. 2002;4:37-44. 
11. Bachrach WH, Hofmann AF. Ursodeoxycholic acid in the treatment of cholesterol cholelithiasis. Part I. Dig Dis Sci. 1982;27:737-61.

12. Roma MG, Toledo FD, Boaglio AC, Basiglio CL, Crocenzi FA, Sánchez Pozzi EJ. Ursodeoxycholic acid in cholestasis: Linking action mechanisms to therapeutic applications. Clin Sci. (Lond.) 2011;121:523-44.

13. Leuschner U, Leuschner M, Sieratzki J, Kurtz W, Hübner K, Gallstone dissolution with ursodeoxycholic acid in patients with chronic active hepatitis and two years follow-up. A pilot study. Dig Dis Sci. 1985;30:642-9.

14. Kotb MA. Molecular mechanisms of ursodeoxycholic acid toxicity \& side effects: ursodeoxycholic acid freezes regeneration \& induces hibernation mode. Int J Mol Sci. 2012;13:8882-914.

15. Product information of apo-ursodeoxycholic acid capsules written on April.20.2017. http://www.secure.healthlinks.net.au.

16. Schiedermaier P, Hansen S, Asdonk D, Brensing K, Sauerbruch T. Effects of ursodeoxycholic acid on splanchnic and systemic hemodynamics. A double-blind, cross-over, placebo-controlled study in healthy volunteers. Digestion. 2000;61:107-12.

17. Franken PR, Guglielmi J, Vanhove C, Koulibaly M, Defrise M, Darcourt J, et al. Distribution and dynamics of $\left({ }^{99 m}\right)$ Tc- pertechnetate uptake in the thyroid and other organs assessed by singlephoton emission computed tomography in living mice. Thyroid. 2010;20:519-26.

18. Hingorani M, Spitzweg C, Vassaux G, Newbold K, Melcher A, Pandha H, et al. The biology of the sodium iodide symporter and its potential for targeted gene delivery. Curr Cancer Drug Targets.2010;10:242-67.

19. Piepsz A1, Colarinha P, Gordon I, Hahn K, Olivier P, Roca I, et al. Guidelines for ${ }^{99 \mathrm{~m} T c-D M S A}$ scintigraphy in children. Eur J Nucl Med. 2001;28:BP37-BP41.

20. Biassoni L, Chippington S. Imaging in urinary tract infections: current strategies and new trends. Semin Nucl Med. 2008;38:56-66.

21. Rossleigh MA. Renal infection and vesico-ureteric reflux. Semin Nucl Med. 2007;37:261-8.

22. Melis M, de Swart J, de Visser M, Berndsen SC, Koelewijn S, Valkema R, et al. Dynamic and static small-animal SPECT in rats for monitoring renal function after ${ }^{177}$ Lu-labeled $\mathrm{Tyr}_{3}$-octreotate radionuclide therapy. J Nucl Med. 2010;51:1962-8.

\section{Figures}




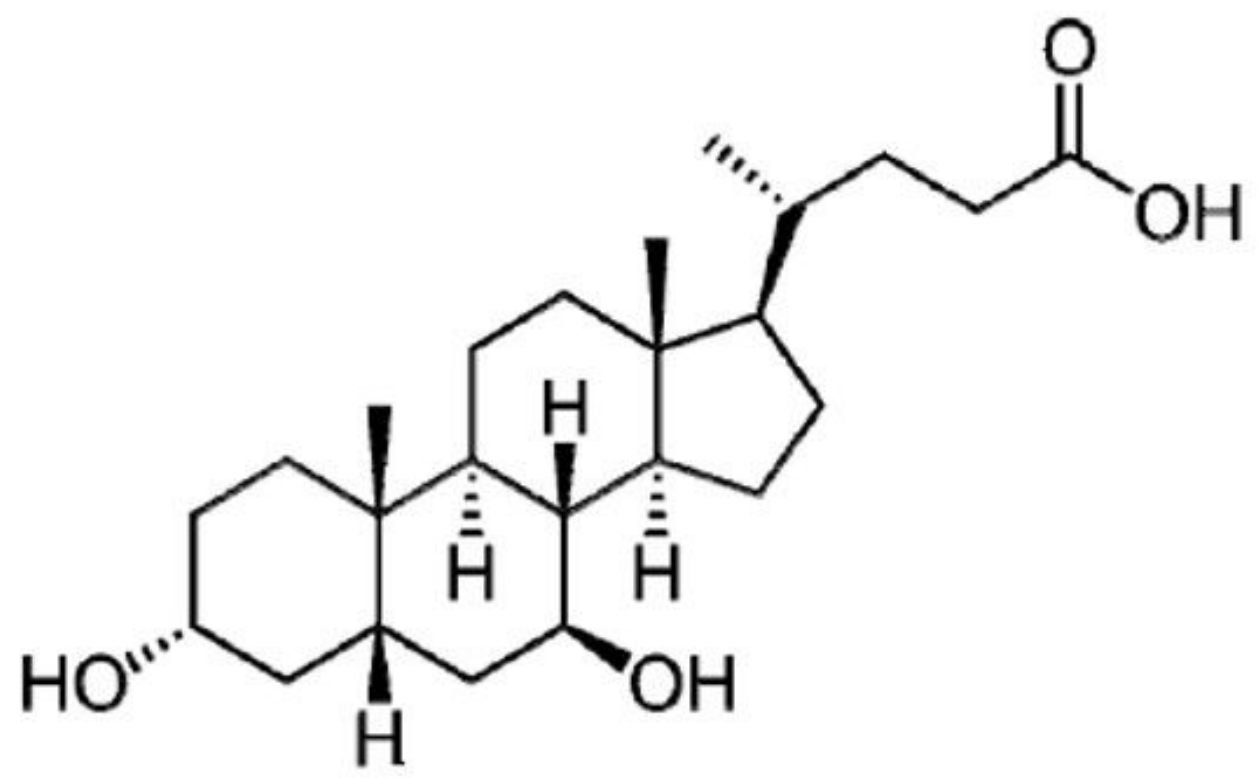

Figure 1

Structure of ursodeoxycholic acid

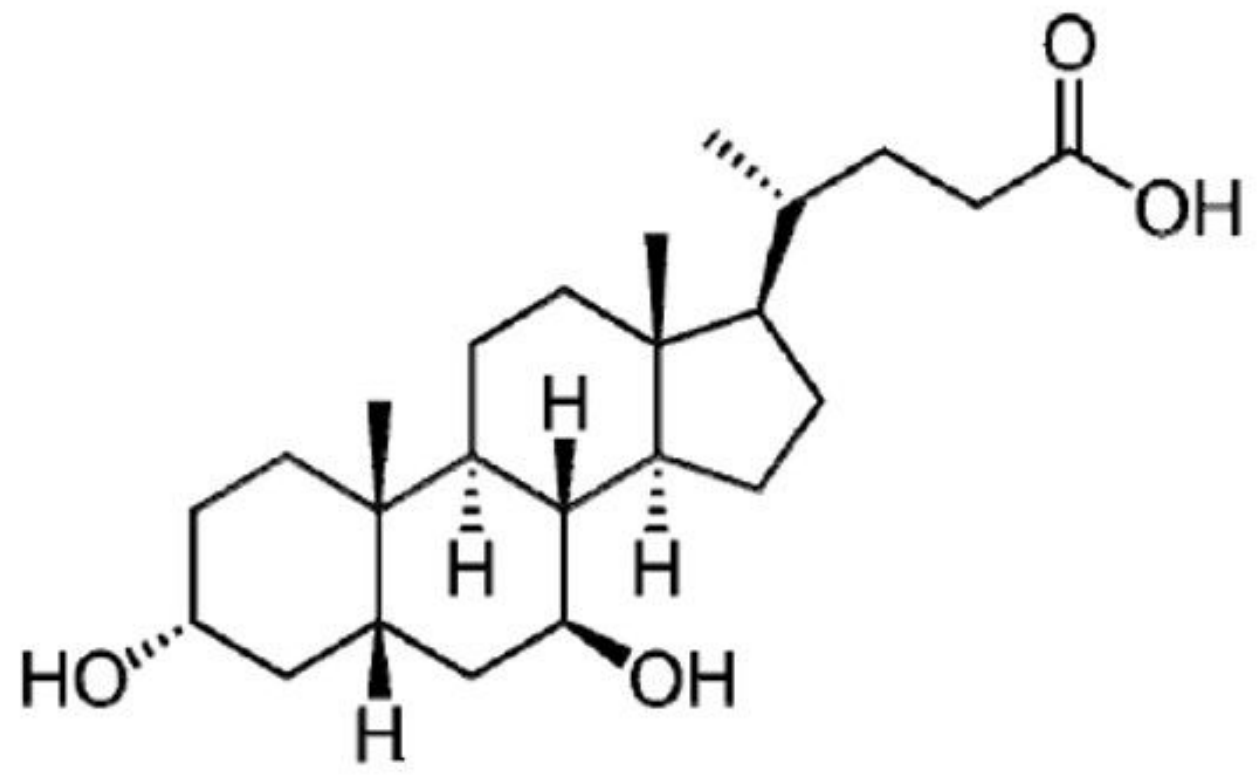

Figure 1

Structure of ursodeoxycholic acid 


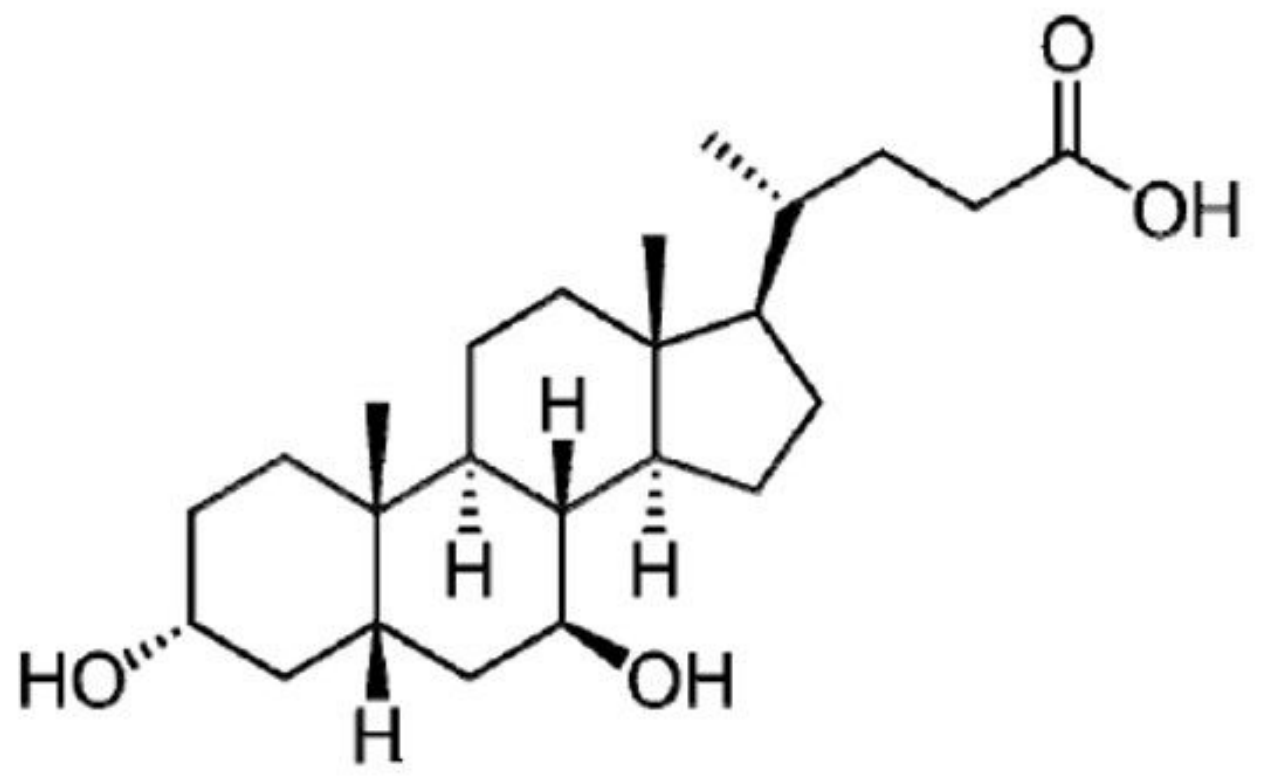

Figure 1

Structure of ursodeoxycholic acid

a

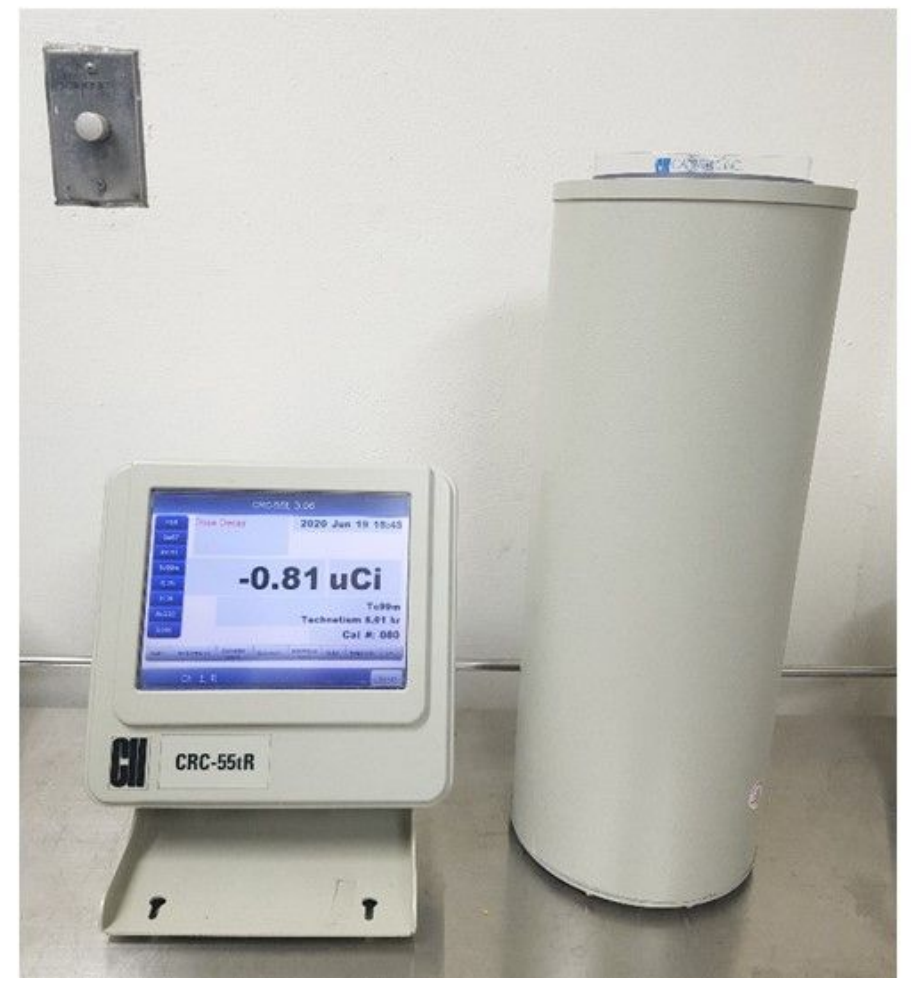

b

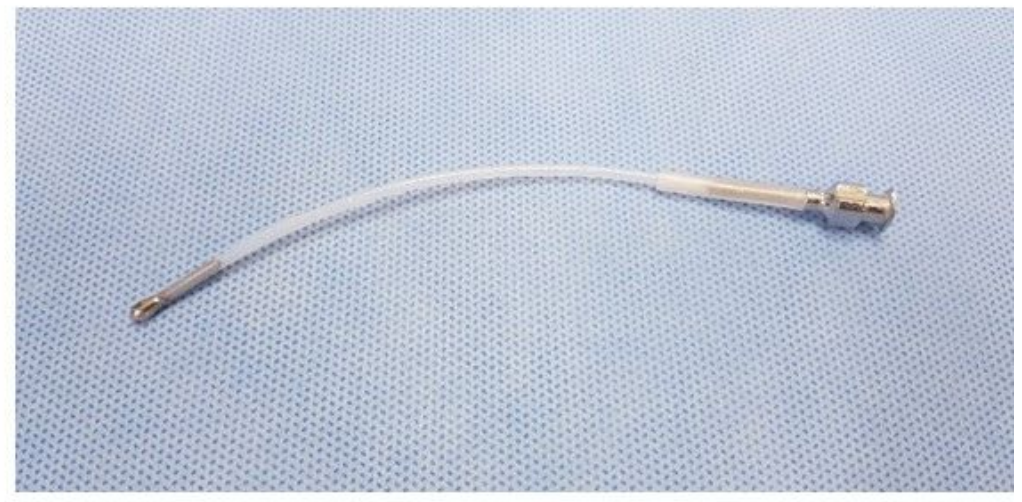

Figure 2

Photographs of the well-type dose calibrator (a) and flexible oral zonde (b) 
$\mathbf{a}$

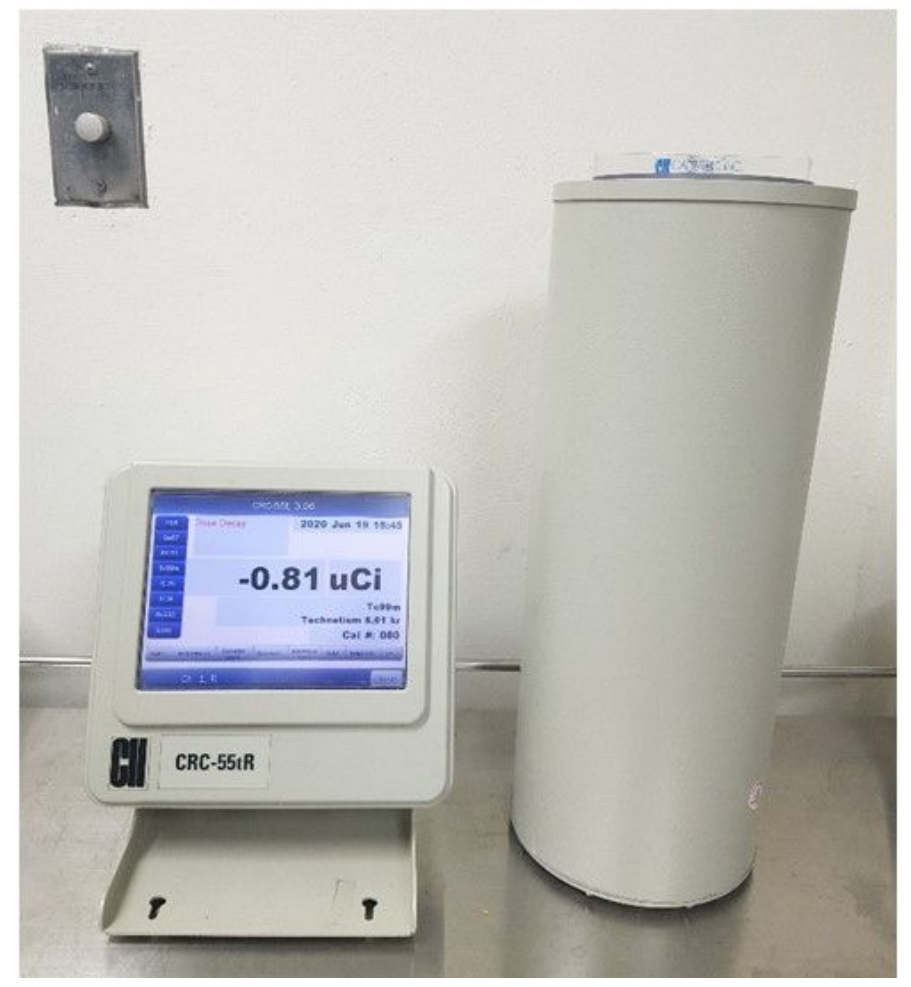

b

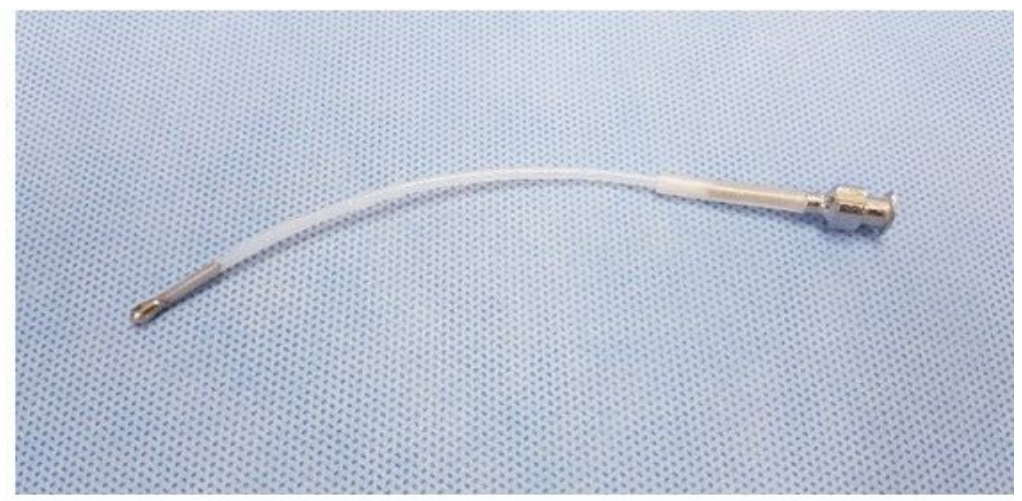

\section{Figure 2}

Photographs of the well-type dose calibrator (a) and flexible oral zonde (b)

$\mathbf{a}$

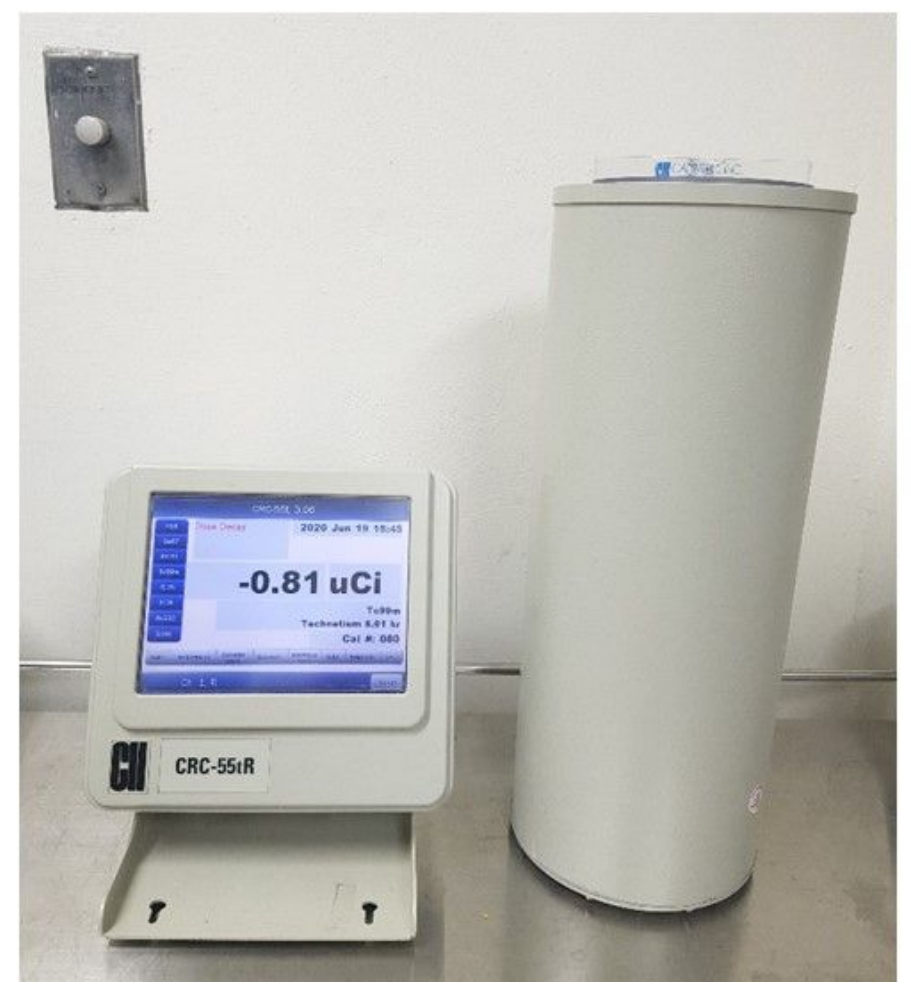

b

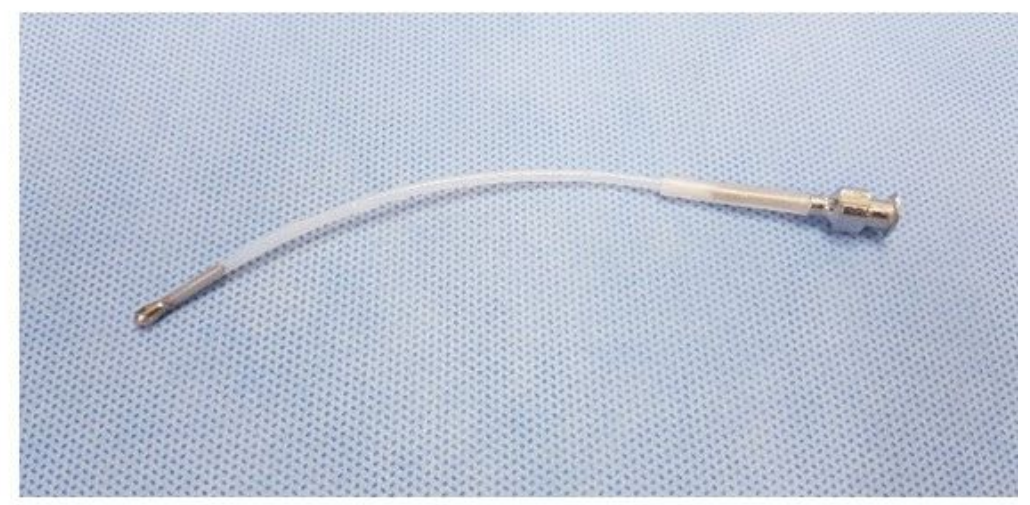


Figure 2

Photographs of the well-type dose calibrator (a) and flexible oral zonde (b)

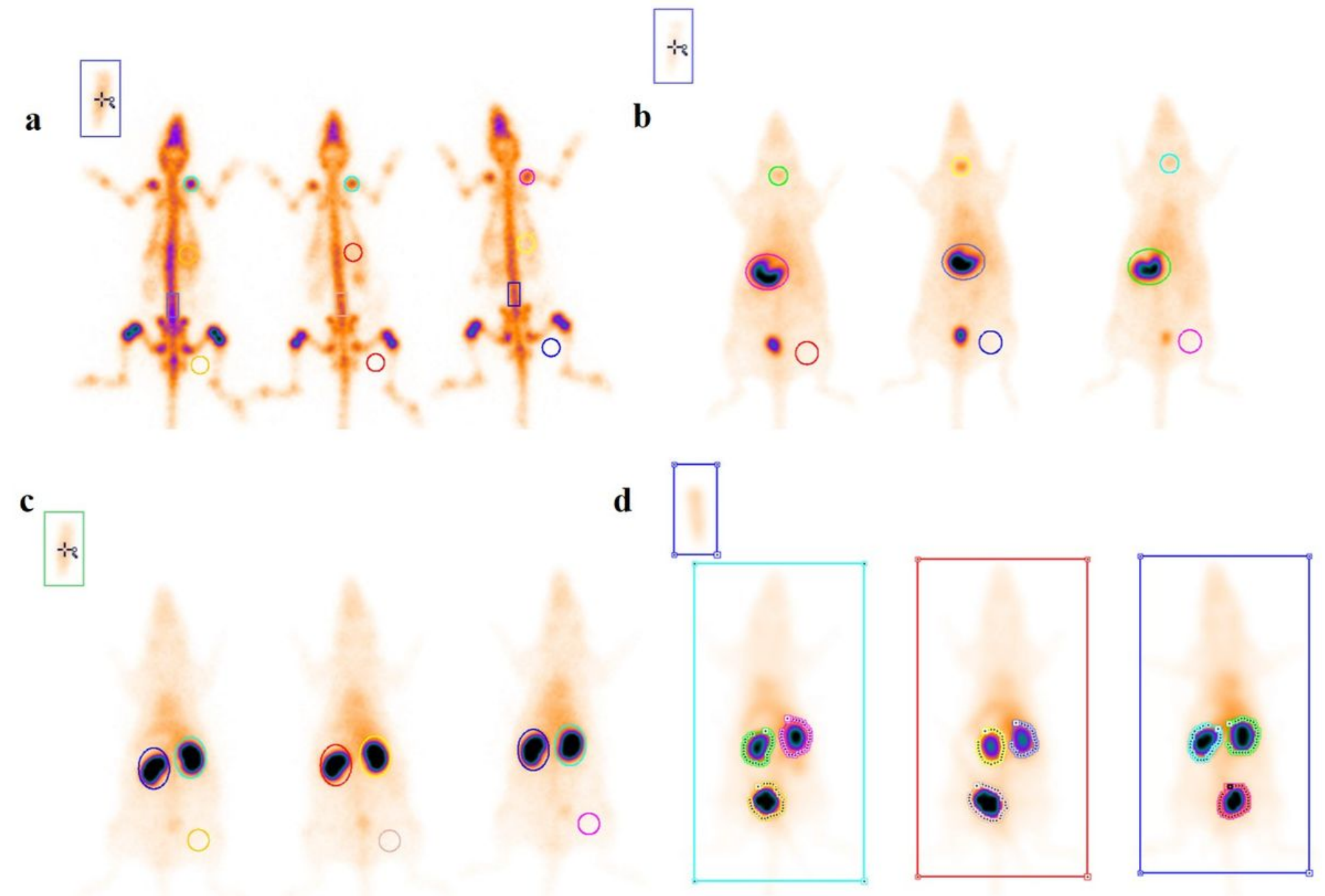

Figure 3

Regions of interest over the relevant organ were drawn depending on the type of radiotracer used (a. Tc99m HDP image without modeling, b. Tc-99m pertechnetate image, c. Tc-99m DMSA image, d. Tc-99m MAG3 image) 


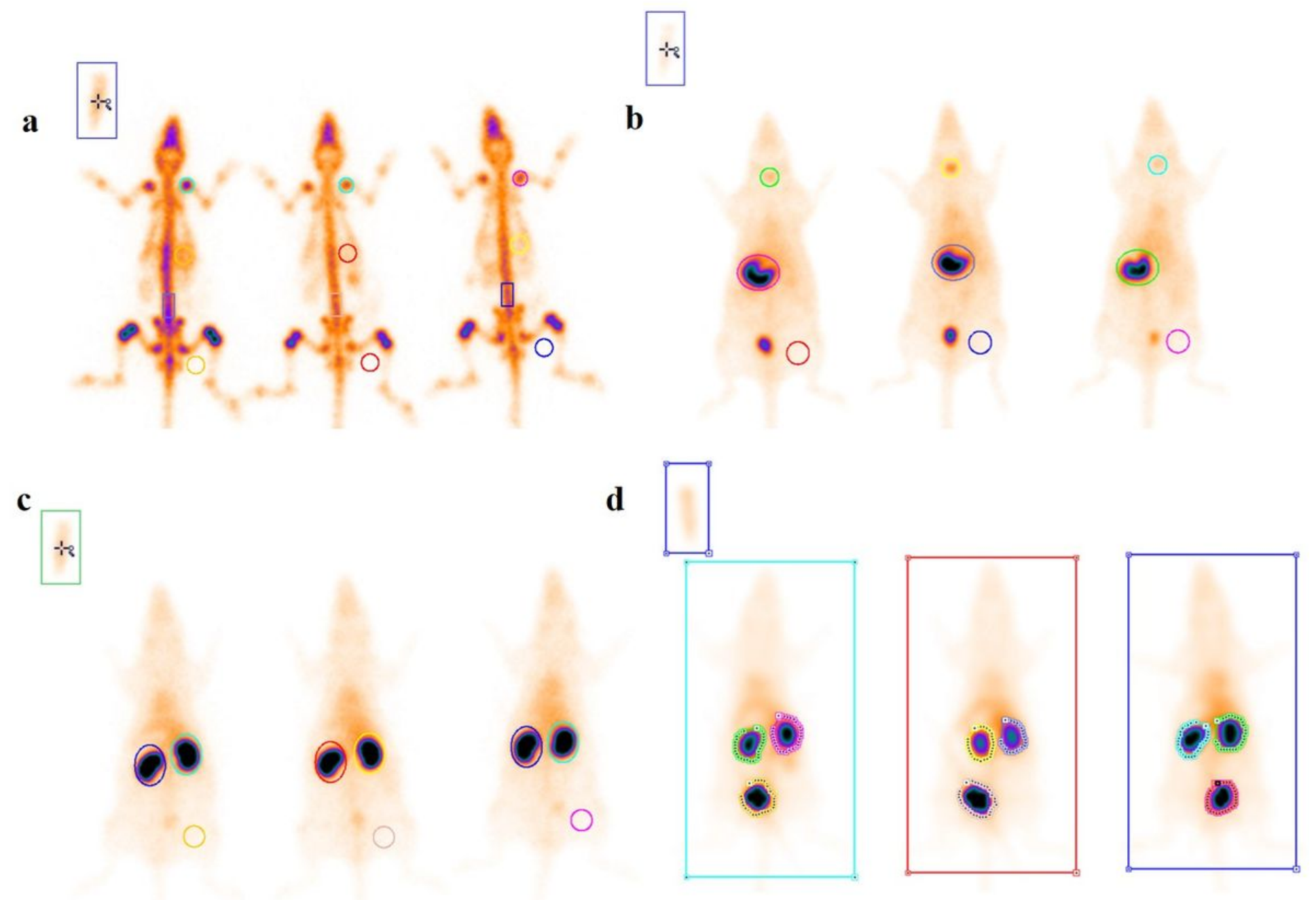

Figure 3

Regions of interest over the relevant organ were drawn depending on the type of radiotracer used (a. Tc99m HDP image without modeling, b. Tc-99m pertechnetate image, c. Tc-99m DMSA image, d. Tc-99m MAG3 image) 


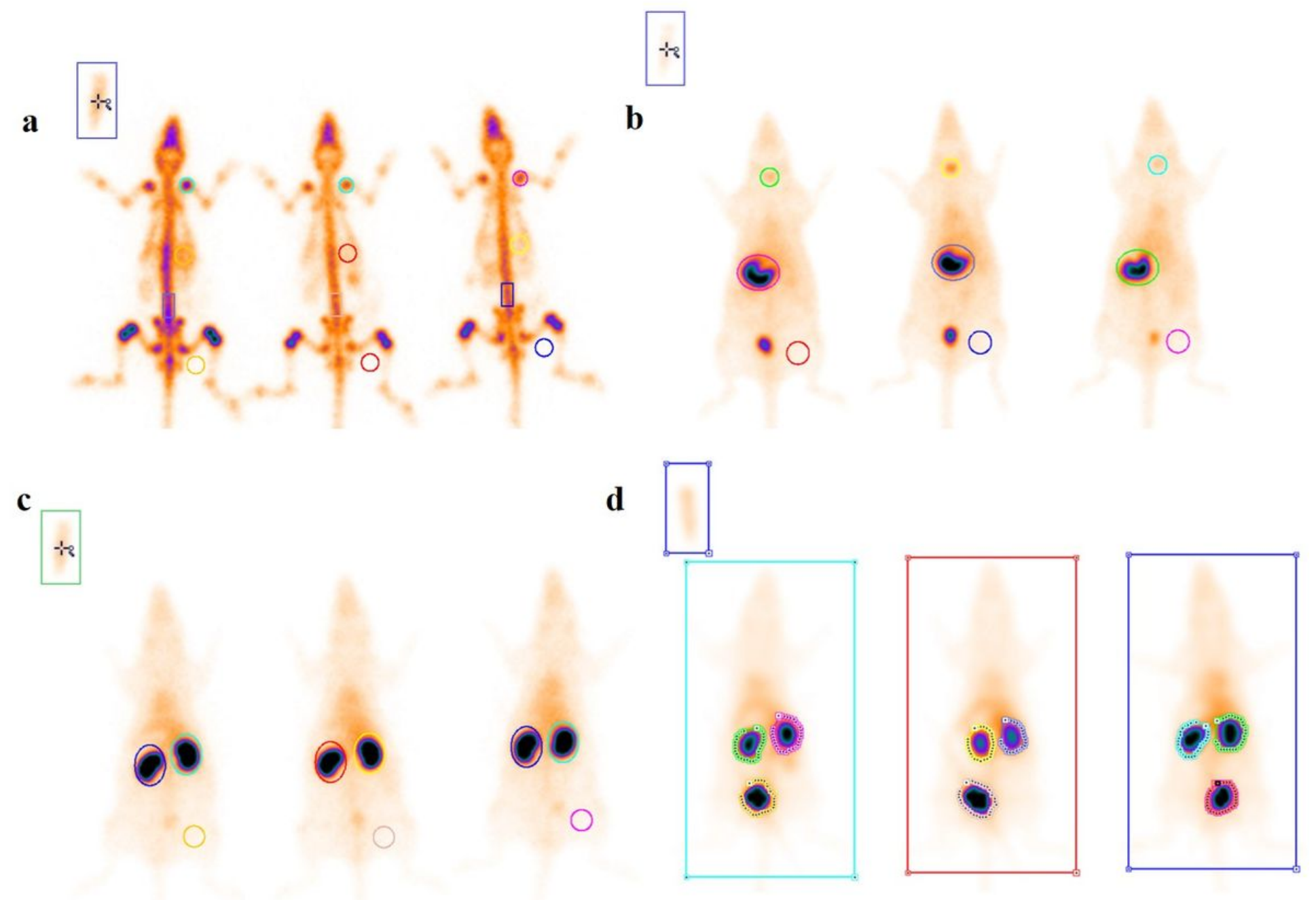

Figure 3

Regions of interest over the relevant organ were drawn depending on the type of radiotracer used (a. Tc99m HDP image without modeling, b. Tc-99m pertechnetate image, c. Tc-99m DMSA image, d. Tc-99m MAG3 image) 
Radioactivity $(\mathrm{kBq})$ in Soft Tissue

(Tc-99m HDP, UDCA 10 mg)

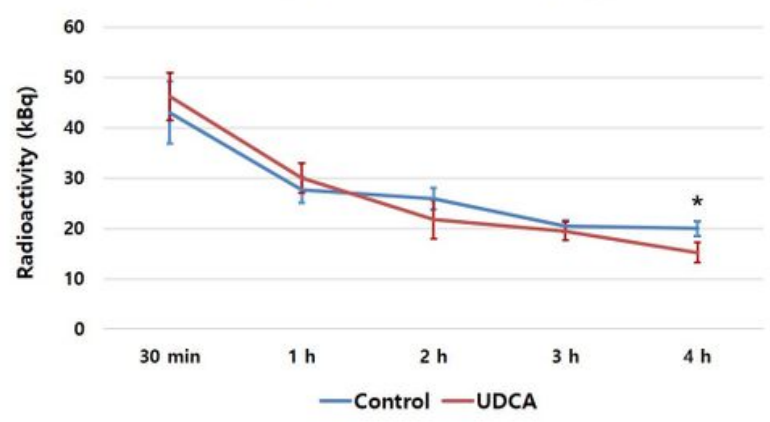

c
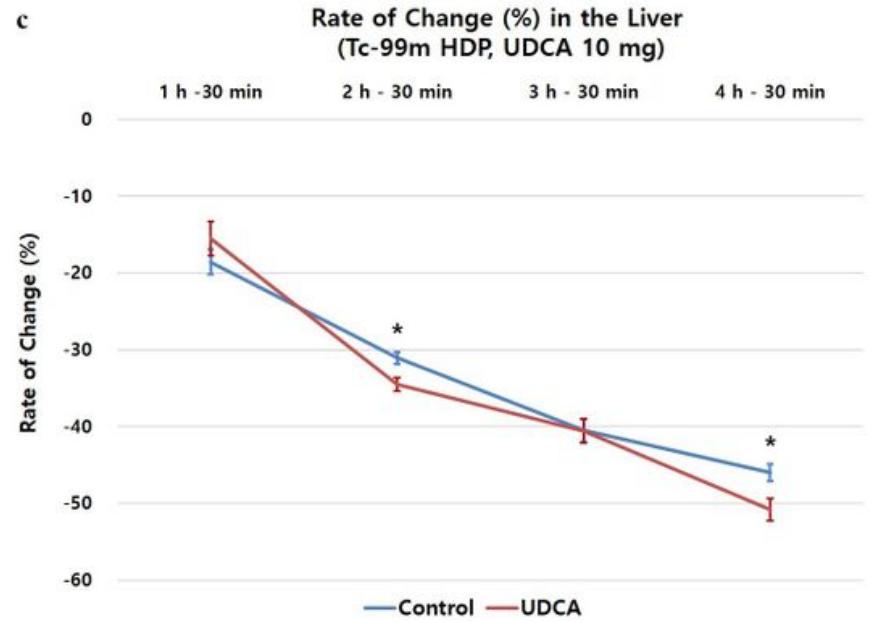

b

Radioactivity/ID (\%) in Soft Tissue

(Tc-99m HDP, UDCA 10 mg)

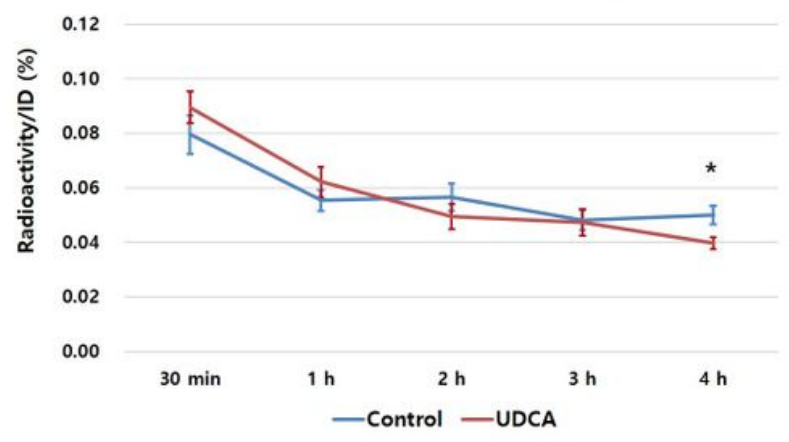

d

Rate of Change (\%) in Soft Tissue

(Tc-99m HDP, UDCA 5 mg)

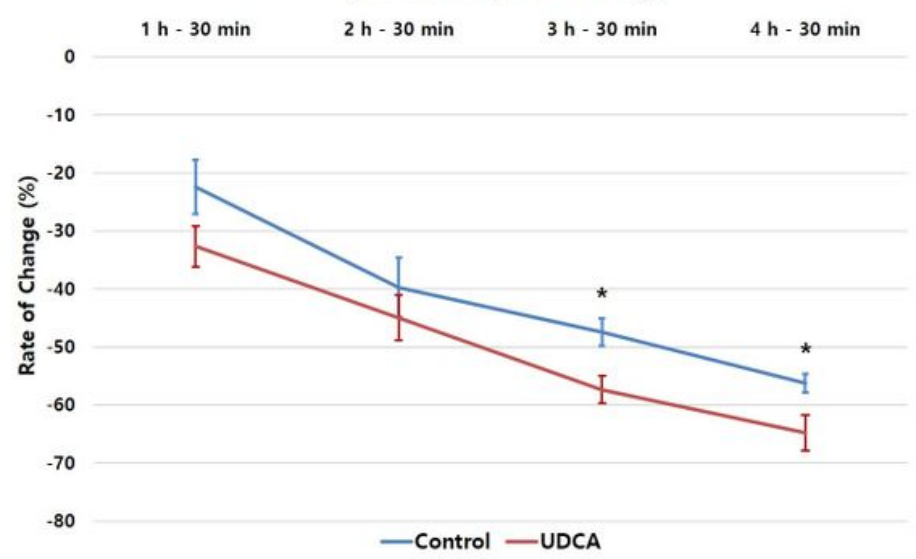

Figure 4

In the image analysis of Tc-99m HDP with 10 mg UDCA, buttock Radioactivity and Radioactivity/ID (\%) were lower in the UDCA group at $4 \mathrm{~h}(\mathrm{a}$ and $\mathrm{b}$ ). The Rate of change (\%) of liver activity was different at $2 \mathrm{~h}$ $-30 \mathrm{~min}$ and $4 \mathrm{~h}-30 \mathrm{~min}$ (c). Rate of change (\%) of buttock activity with $5 \mathrm{mg}$ of UDCA was significantly different at $3 \mathrm{~h}-30 \mathrm{~min}$ and $4 \mathrm{~h}-30 \mathrm{~min}(\mathrm{~d})$. 


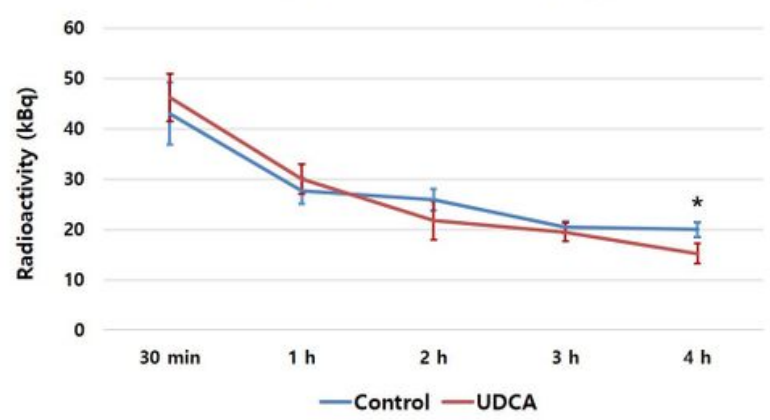

c
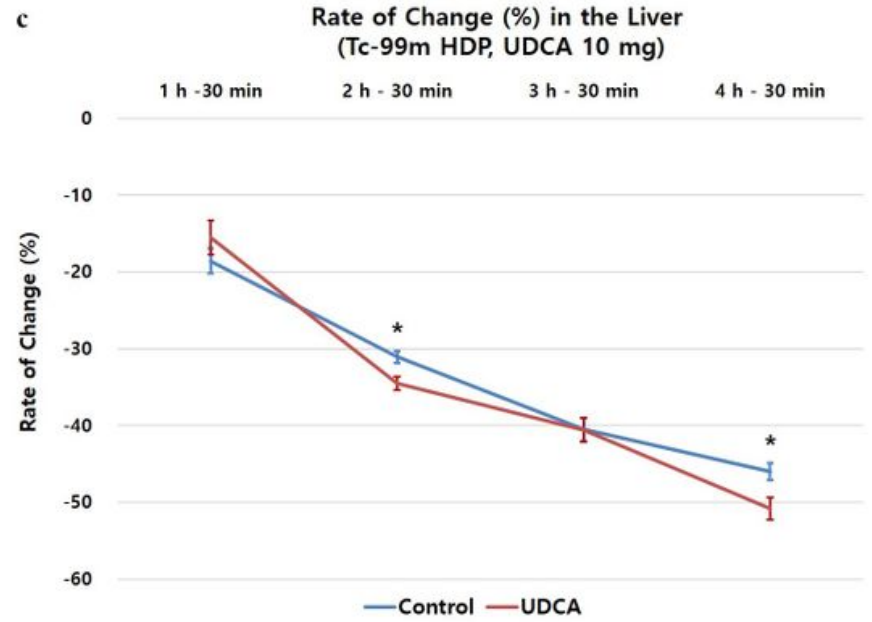

Radioactivity/ID (\%) in Soft Tissue (Tc-99m HDP, UDCA 10 mg)

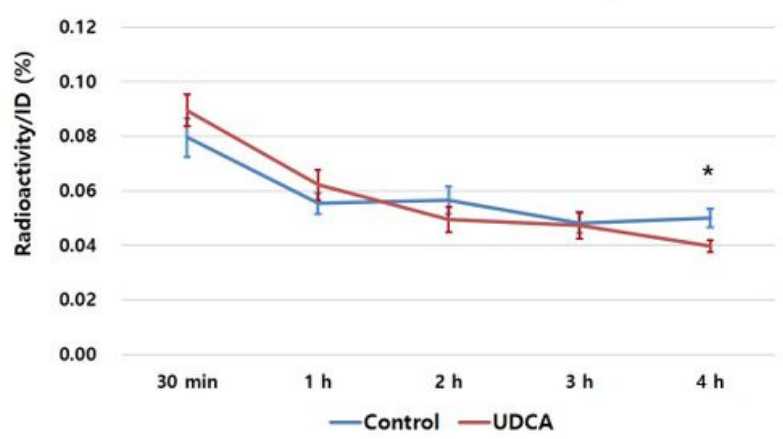

d

Rate of Change (\%) in Soft Tissue (Tc-99m HDP, UDCA 5 mg)

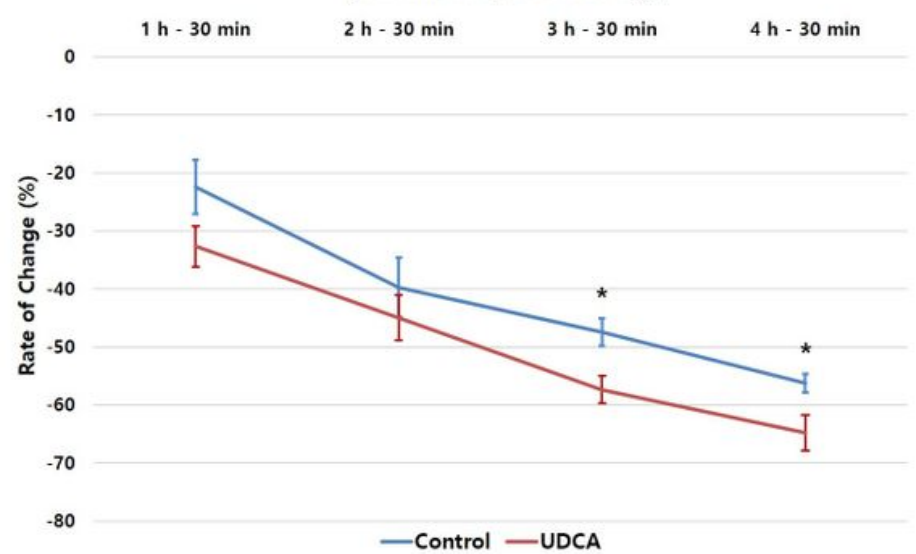

Figure 4

In the image analysis of Tc-99m HDP with 10 mg UDCA, buttock Radioactivity and Radioactivity/ID (\%) were lower in the UDCA group at $4 \mathrm{~h}(\mathrm{a}$ and $\mathrm{b}$ ). The Rate of change (\%) of liver activity was different at $2 \mathrm{~h}$ - $30 \mathrm{~min}$ and $4 \mathrm{~h}-30 \mathrm{~min}$ (c). Rate of change (\%) of buttock activity with $5 \mathrm{mg}$ of UDCA was significantly different at $3 \mathrm{~h}-30 \mathrm{~min}$ and $4 \mathrm{~h}-30 \mathrm{~min}(\mathrm{~d})$. 


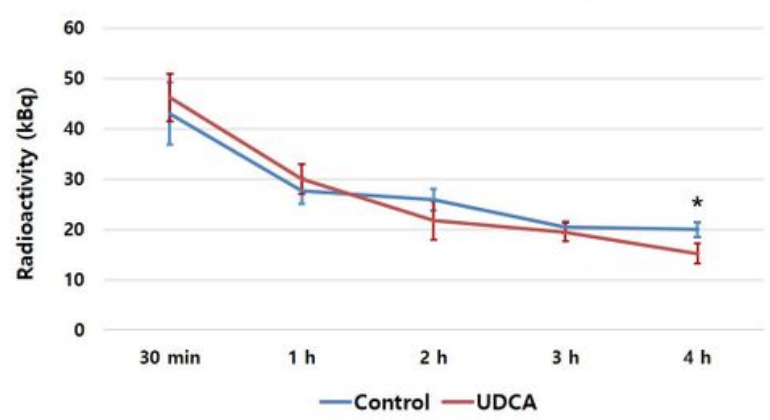

c
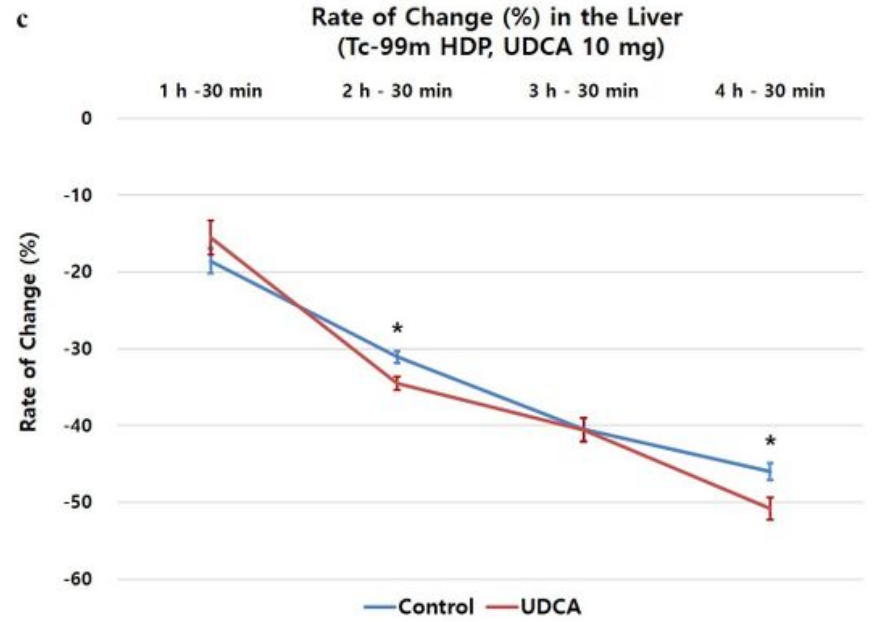

Radioactivity/ID (\%) in Soft Tissue (Tc-99m HDP, UDCA 10 mg)

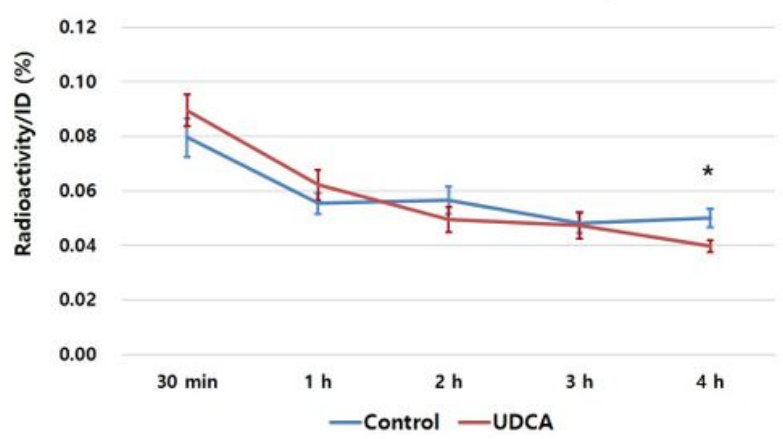

d

Rate of Change (\%) in Soft Tissue (Tc-99m HDP, UDCA 5 mg)

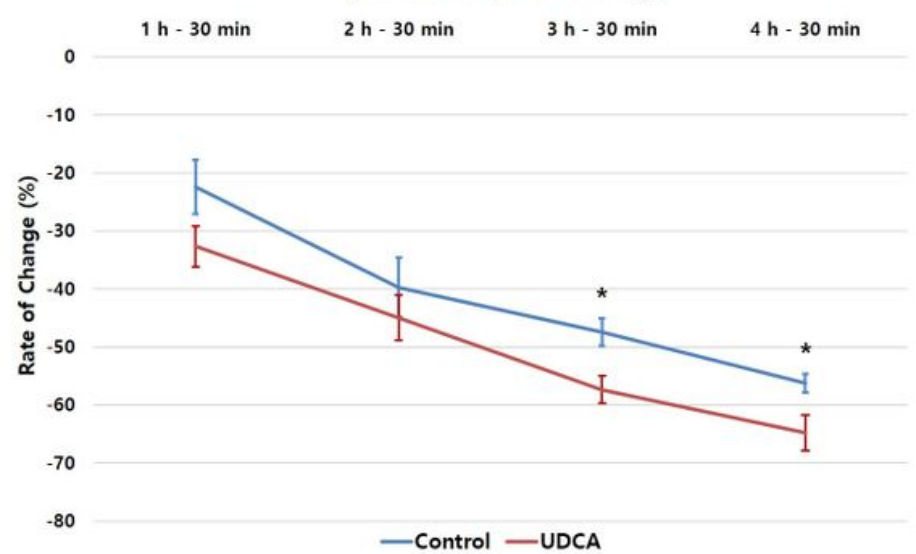

Figure 4

In the image analysis of Tc-99m HDP with 10 mg UDCA, buttock Radioactivity and Radioactivity/ID (\%) were lower in the UDCA group at $4 \mathrm{~h}(\mathrm{a}$ and $\mathrm{b}$ ). The Rate of change (\%) of liver activity was different at $2 \mathrm{~h}$ - $30 \mathrm{~min}$ and $4 \mathrm{~h}-30 \mathrm{~min}$ (c). Rate of change (\%) of buttock activity with $5 \mathrm{mg}$ of UDCA was significantly different at $3 \mathrm{~h}-30 \mathrm{~min}$ and $4 \mathrm{~h}-30 \mathrm{~min}(\mathrm{~d})$. 


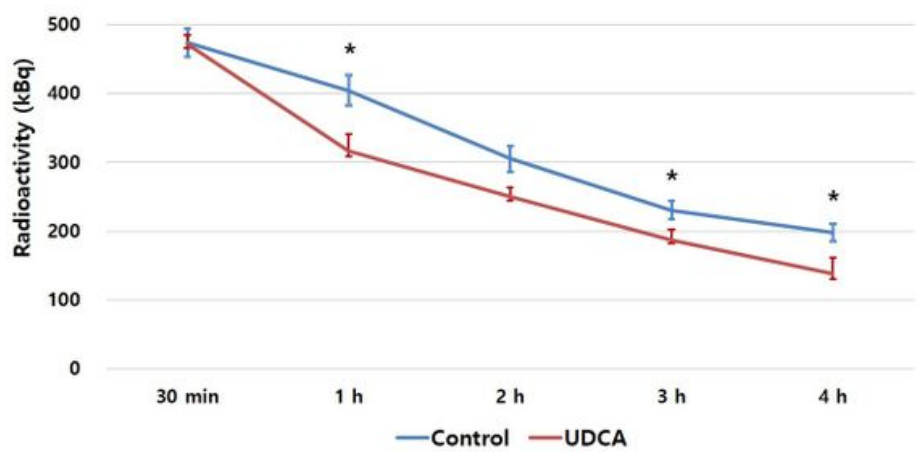

c

Radioactivity/ID (\%) in Soft Tissue (Tc-99m pertechnetate, UDCA $10 \mathrm{mg}$ )

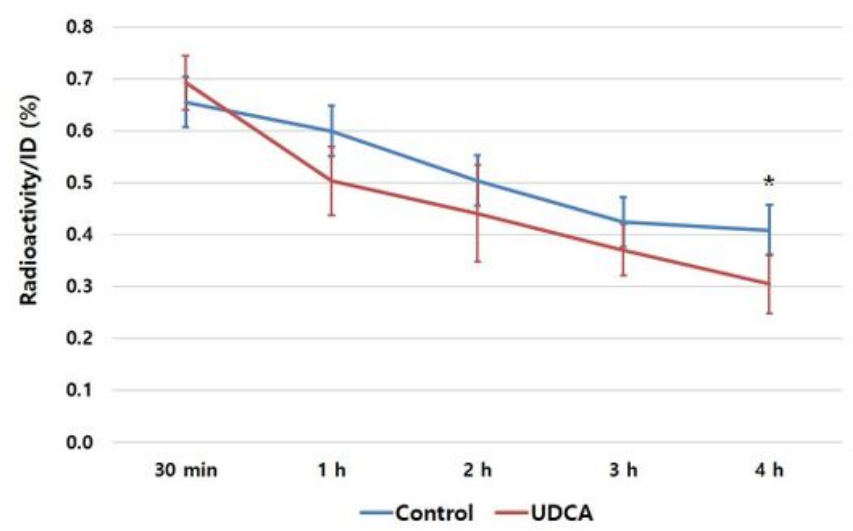

b

Rate of Change (\%) in Soft Tissue (Tc-99m pertechnetate, UDCA $10 \mathrm{mg}$ )

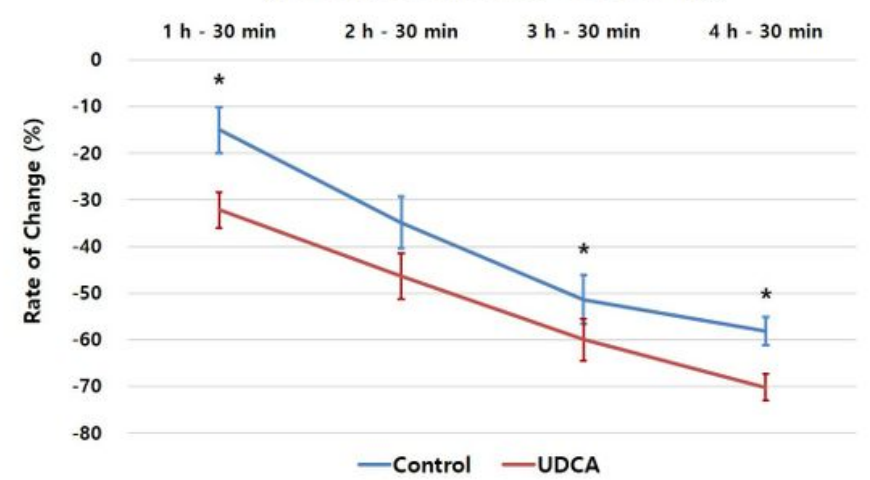

d Rate of Change (\%) in the Thyroid Gland (Tc-99m pertechnetate, UDCA $10 \mathrm{mg}$ )

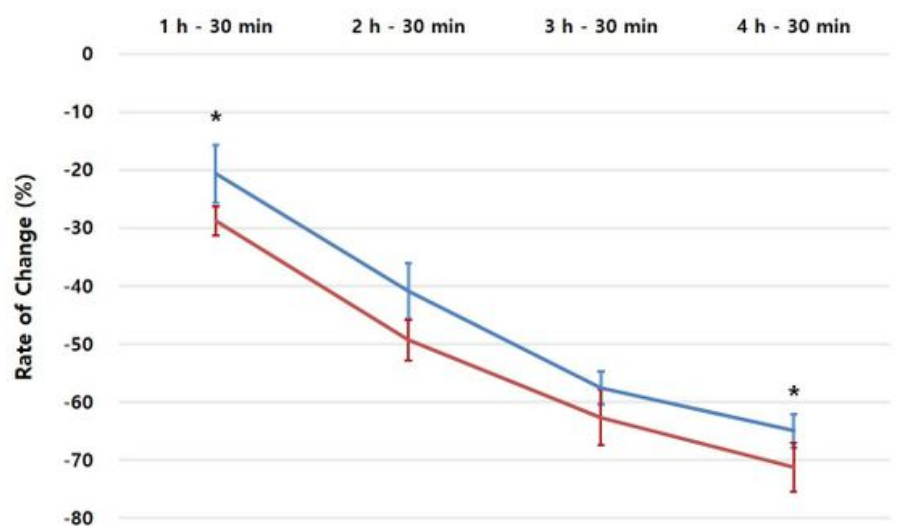

- Control -UDCA

\section{Figure 5}

In the image analysis of Tc-99m pertechnetate, Radioactivity of the buttock was greater in the Control group at 1, 3, and $4 \mathrm{~h} \mathrm{(a).} \mathrm{Rates} \mathrm{of} \mathrm{change} \mathrm{( \% )} \mathrm{in} \mathrm{the} \mathrm{buttock} \mathrm{were} \mathrm{also} \mathrm{different} \mathrm{at} 1 \mathrm{~h}-30 \mathrm{~min}, 3 \mathrm{~h}-30$ min, and $4 \mathrm{~h}-30 \mathrm{~min}(\mathrm{~b})$. Radioactivity/ID (\%) in the buttock was lower in the UDCA group at $4 \mathrm{~h}$ (c). Rate of change (\%) in the thyroid gland was different at $1 \mathrm{~h}-30 \mathrm{~min}$ and $4 \mathrm{~h}-30 \mathrm{~min}(\mathrm{~d})$. 


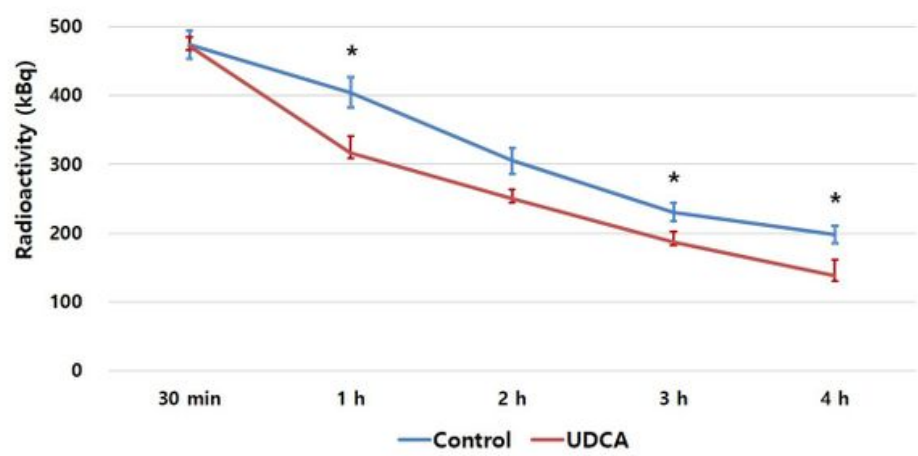

c

Radioactivity/ID (\%) in Soft Tissue (Tc-99m pertechnetate, UDCA $10 \mathrm{mg}$ )

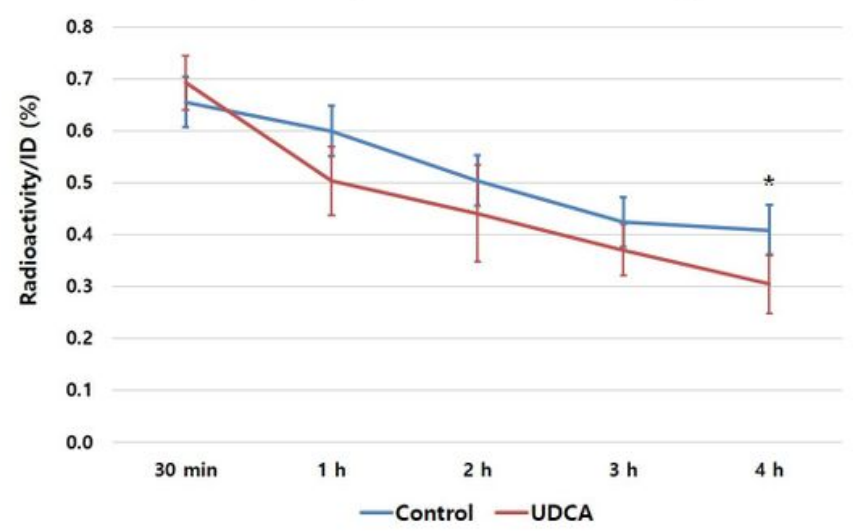

b

Rate of Change (\%) in Soft Tissue (Tc-99m pertechnetate, UDCA $10 \mathrm{mg}$ )

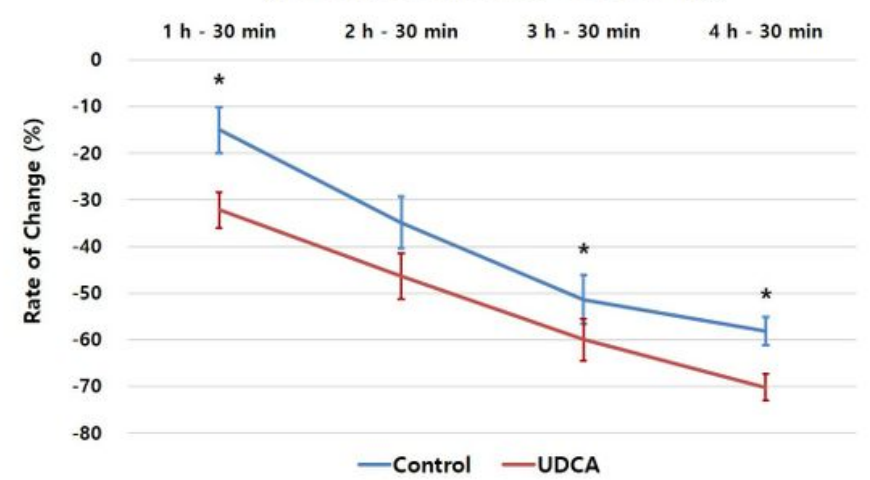

d Rate of Change (\%) in the Thyroid Gland (Tc-99m pertechnetate, UDCA $10 \mathrm{mg}$ )

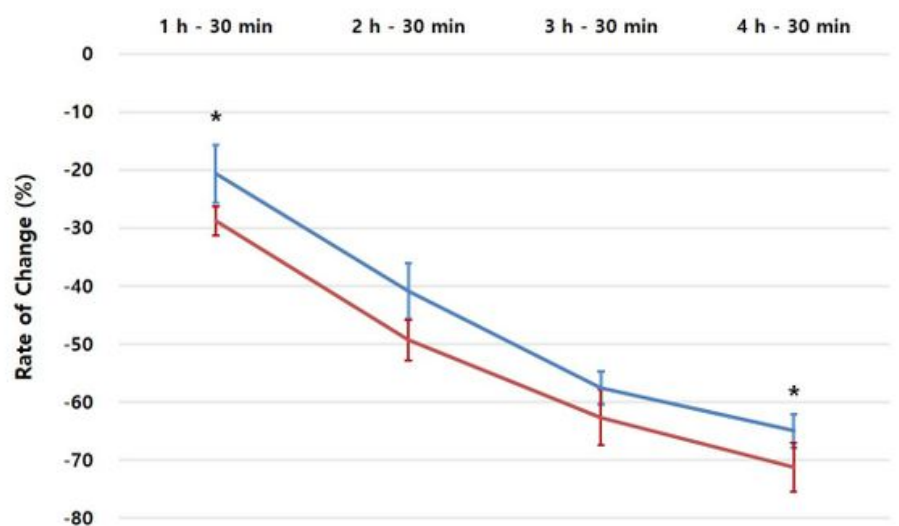

- Control -UDCA

\section{Figure 5}

In the image analysis of Tc-99m pertechnetate, Radioactivity of the buttock was greater in the Control group at 1, 3, and $4 \mathrm{~h} \mathrm{(a).} \mathrm{Rates} \mathrm{of} \mathrm{change} \mathrm{( \% )} \mathrm{in} \mathrm{the} \mathrm{buttock} \mathrm{were} \mathrm{also} \mathrm{different} \mathrm{at} 1 \mathrm{~h}-30 \mathrm{~min}, 3 \mathrm{~h}-30$ min, and $4 \mathrm{~h}-30 \mathrm{~min}(\mathrm{~b})$. Radioactivity/ID (\%) in the buttock was lower in the UDCA group at $4 \mathrm{~h}$ (c). Rate of change (\%) in the thyroid gland was different at $1 \mathrm{~h}-30 \mathrm{~min}$ and $4 \mathrm{~h}-30 \mathrm{~min}$ (d). 


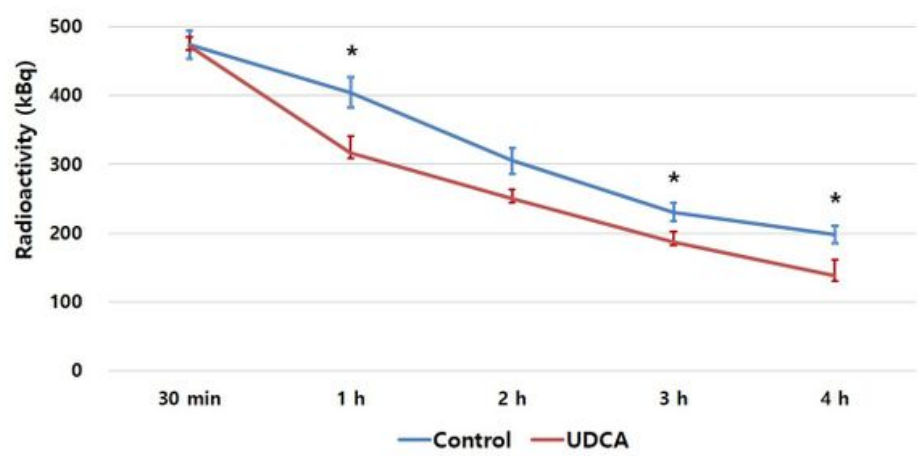

c

Radioactivity/ID (\%) in Soft Tissue (Tc-99m pertechnetate, UDCA $10 \mathrm{mg}$ )

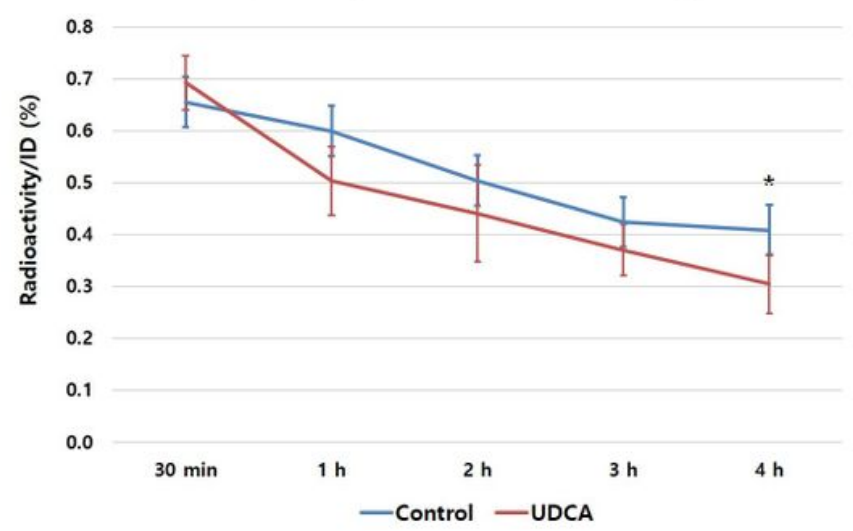

b

Rate of Change (\%) in Soft Tissue (Tc-99m pertechnetate, UDCA $10 \mathrm{mg}$ )

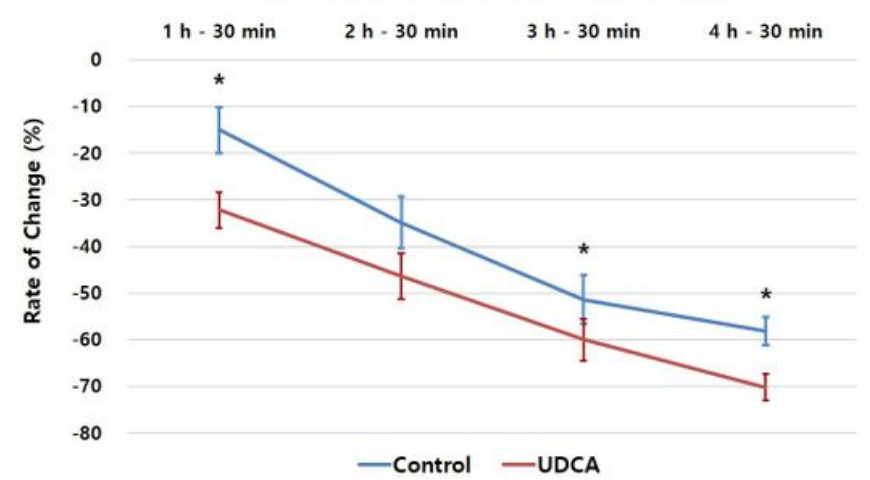

d Rate of Change (\%) in the Thyroid Gland (Tc-99m pertechnetate, UDCA $10 \mathrm{mg}$ )

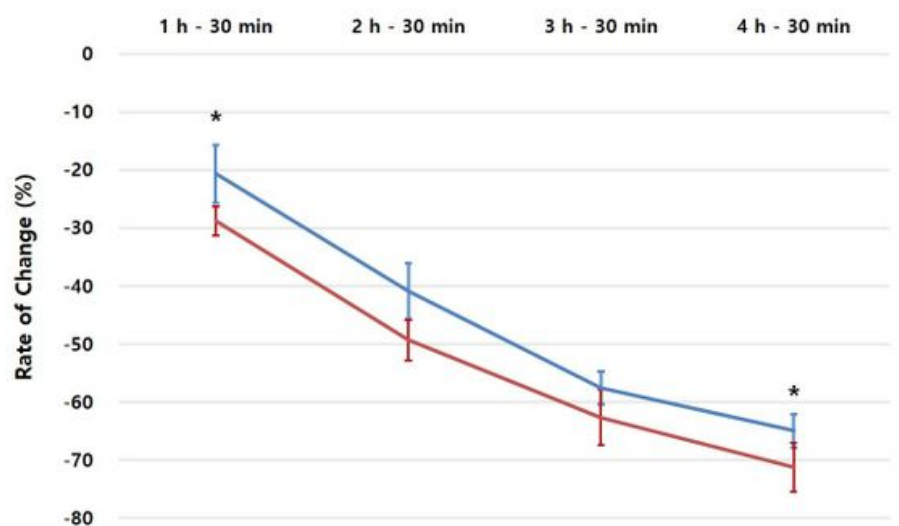

- Control -UDCA

\section{Figure 5}

In the image analysis of Tc-99m pertechnetate, Radioactivity of the buttock was greater in the Control group at 1, 3, and $4 \mathrm{~h} \mathrm{(a).} \mathrm{Rates} \mathrm{of} \mathrm{change} \mathrm{( \% )} \mathrm{in} \mathrm{the} \mathrm{buttock} \mathrm{were} \mathrm{also} \mathrm{different} \mathrm{at} 1 \mathrm{~h}-30 \mathrm{~min}, 3 \mathrm{~h}-30$ min, and $4 \mathrm{~h}-30 \mathrm{~min}(\mathrm{~b})$. Radioactivity/ID (\%) in the buttock was lower in the UDCA group at $4 \mathrm{~h}$ (c). Rate of change (\%) in the thyroid gland was different at $1 \mathrm{~h}-30 \mathrm{~min}$ and $4 \mathrm{~h}-30 \mathrm{~min}$ (d). 


\section{Rate of Change (\%) in the Kidney \\ (Tc-99m DMSA, UDCA 10 mg)}

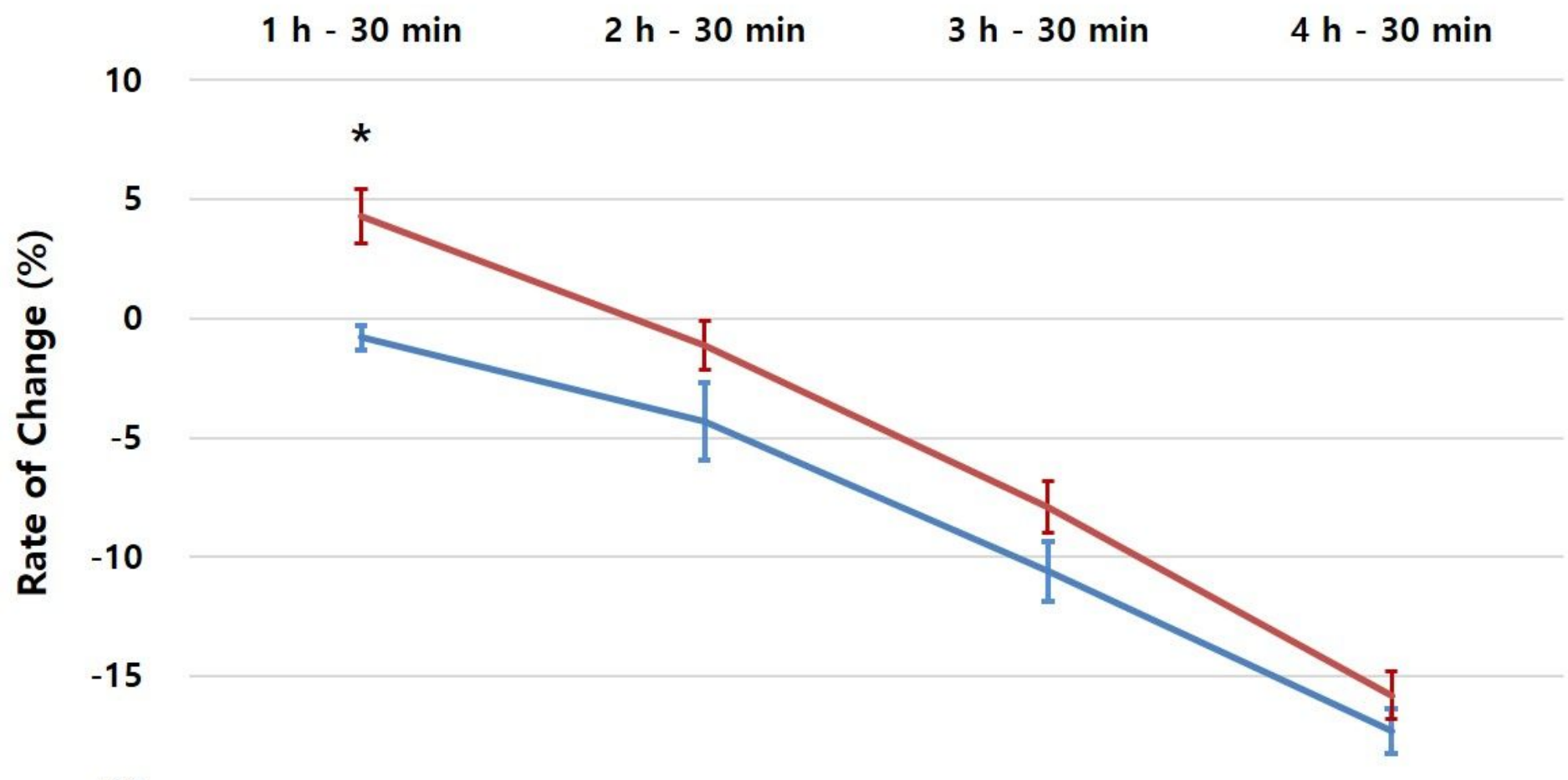

$-20$

- Control -UDCA

Figure 6

In the image analysis of Tc-99m DMSA, Radioactivity of the kidney increased more in the UDCA group compared to the Control group at the early time point of $1 \mathrm{~h}-30 \mathrm{~min}$. 


\section{Rate of Change (\%) in the Kidney \\ (Tc-99m DMSA, UDCA 10 mg)}

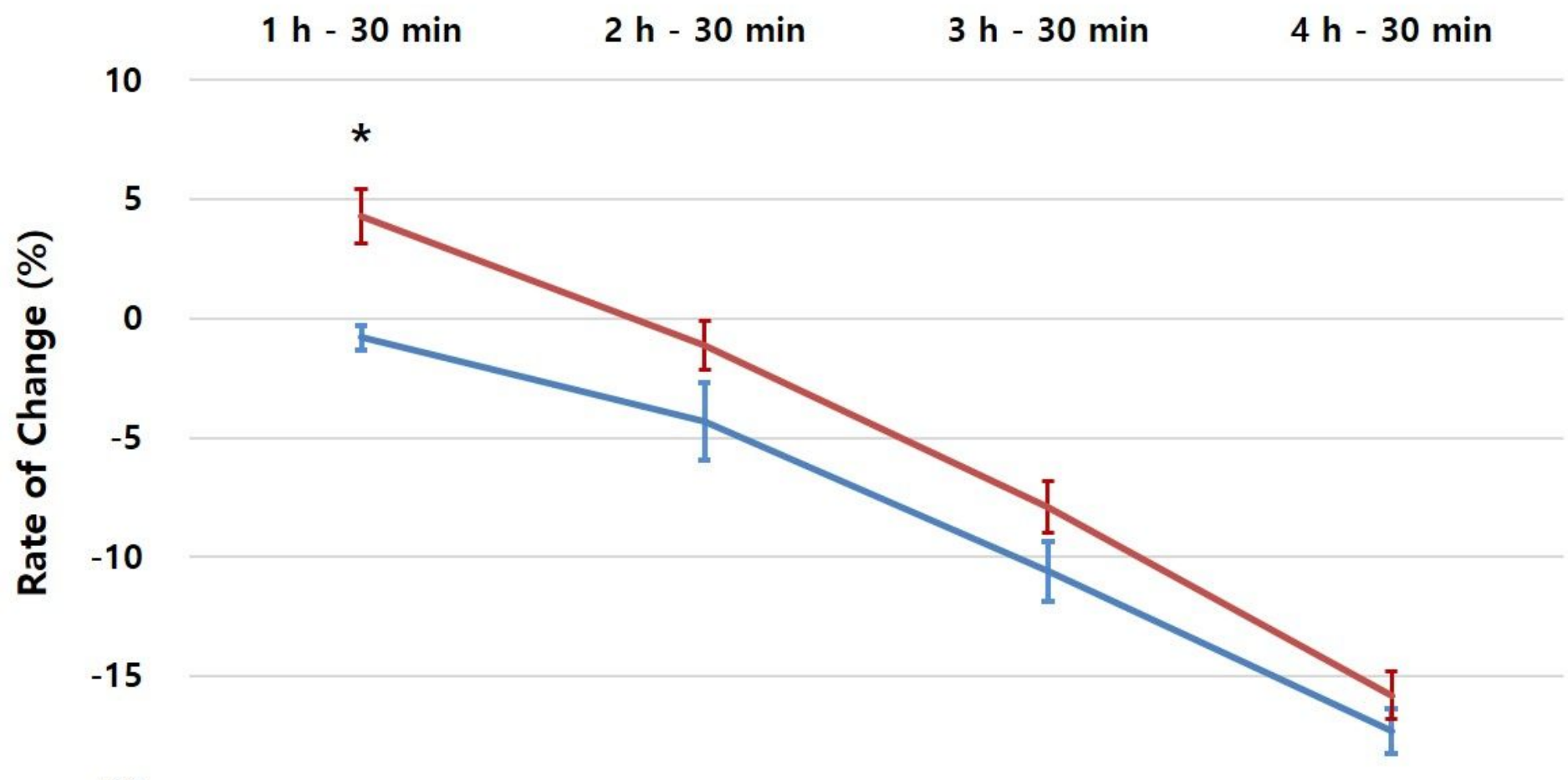

$-20$

- Control -UDCA

Figure 6

In the image analysis of Tc-99m DMSA, Radioactivity of the kidney increased more in the UDCA group compared to the Control group at the early time point of $1 \mathrm{~h}-30 \mathrm{~min}$. 


\section{Rate of Change (\%) in the Kidney \\ (Tc-99m DMSA, UDCA 10 mg)}

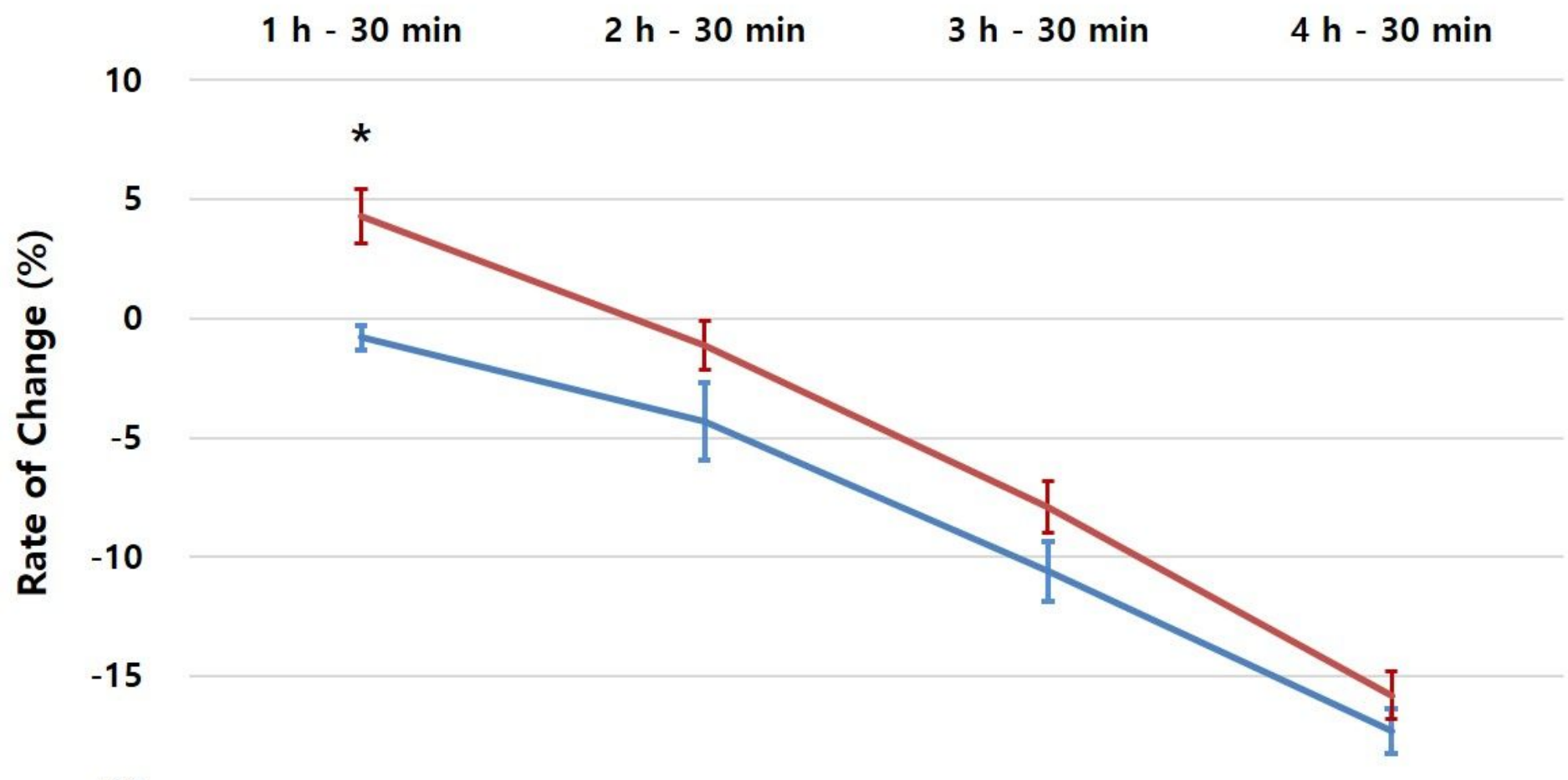

$-20$

- Control -UDCA

Figure 6

In the image analysis of Tc-99m DMSA, Radioactivity of the kidney increased more in the UDCA group compared to the Control group at the early time point of $1 \mathrm{~h}-30 \mathrm{~min}$. 


\section{Total Body Radioactivity Measured by Dose Calibrator}

40

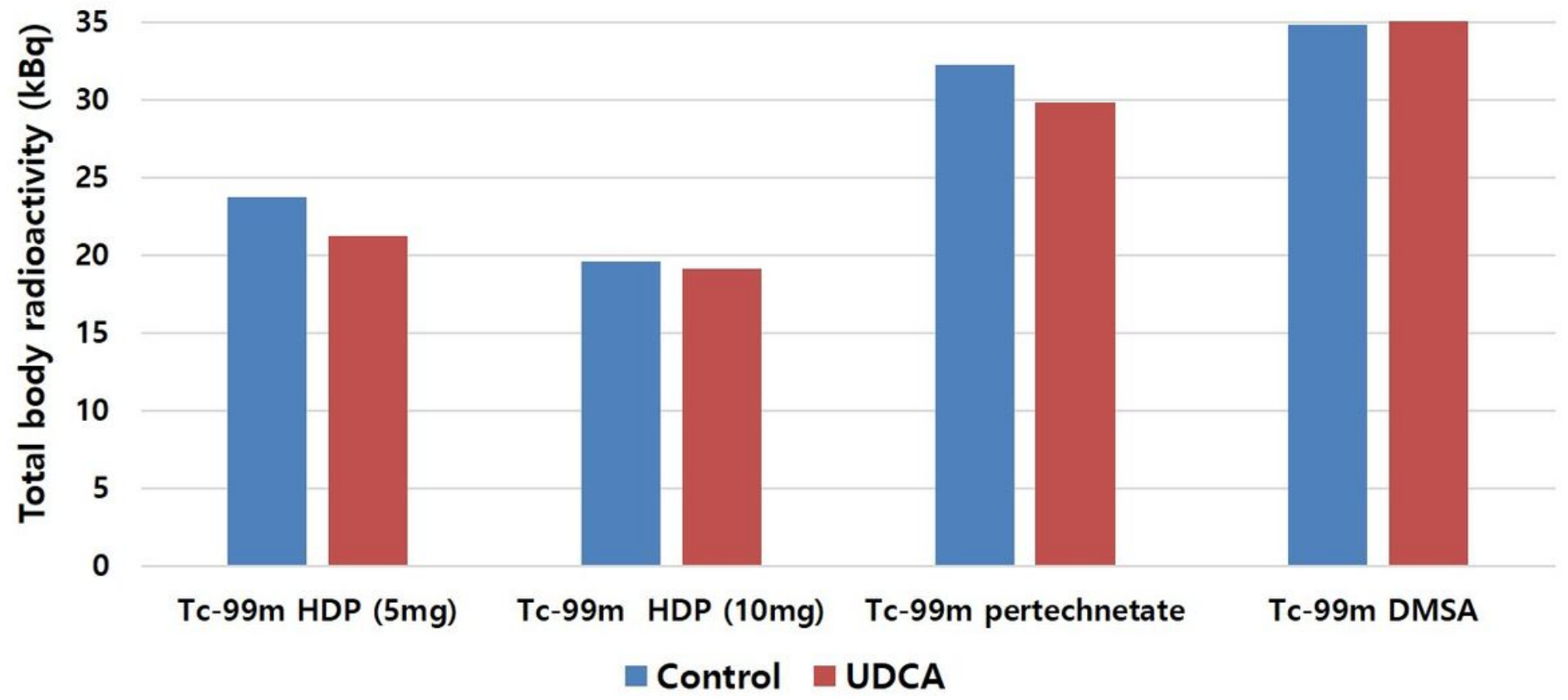

Figure 7

Total body radioactivity after all 5 image acquisition time points. Total body radioactivity was measured with a dose calibrator and was generally lower in the UDCA group, except for in the Tc-99m DMSA experiment. The difference between the 2 groups was not statistically significant. 


\section{Total Body Radioactivity Measured by Dose Calibrator}

40

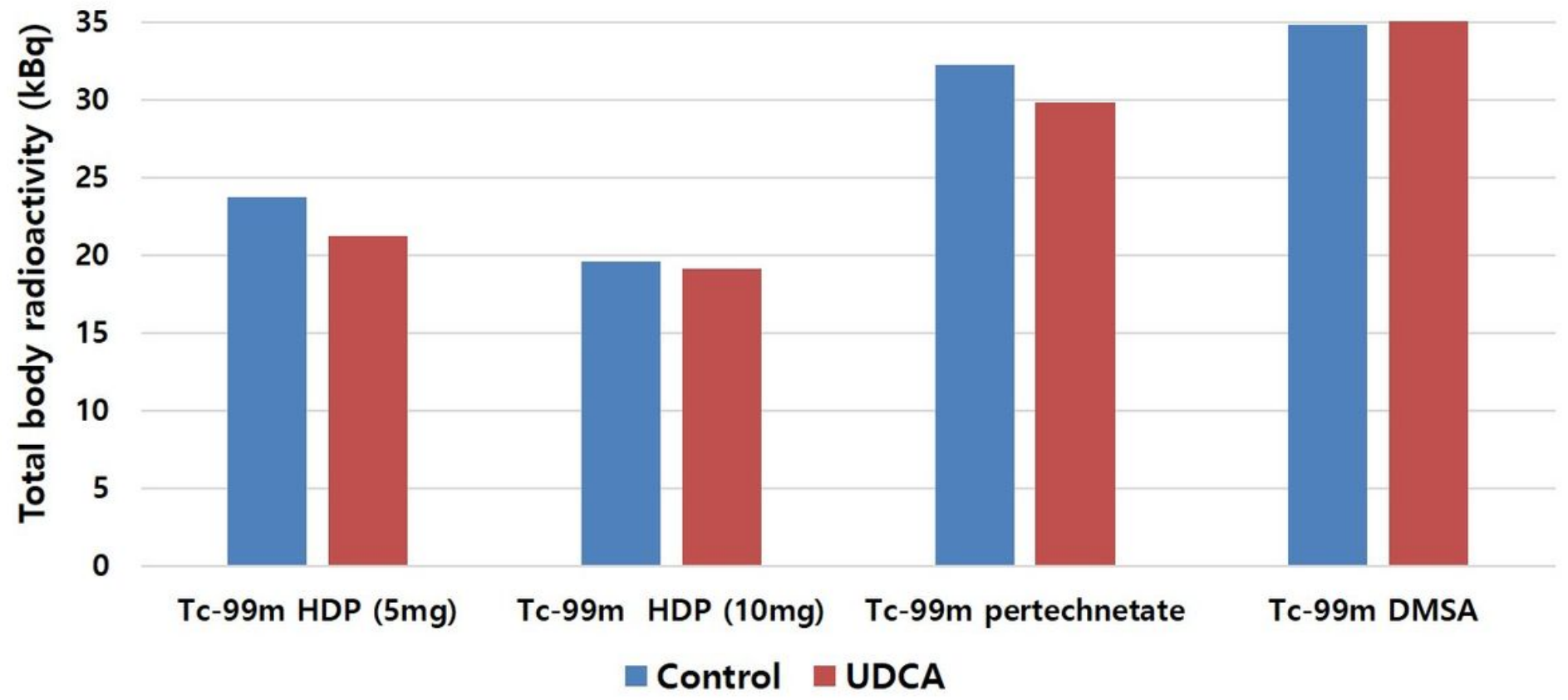

Figure 7

Total body radioactivity after all 5 image acquisition time points. Total body radioactivity was measured with a dose calibrator and was generally lower in the UDCA group, except for in the Tc-99m DMSA experiment. The difference between the 2 groups was not statistically significant. 


\section{Total Body Radioactivity Measured by Dose Calibrator}

40

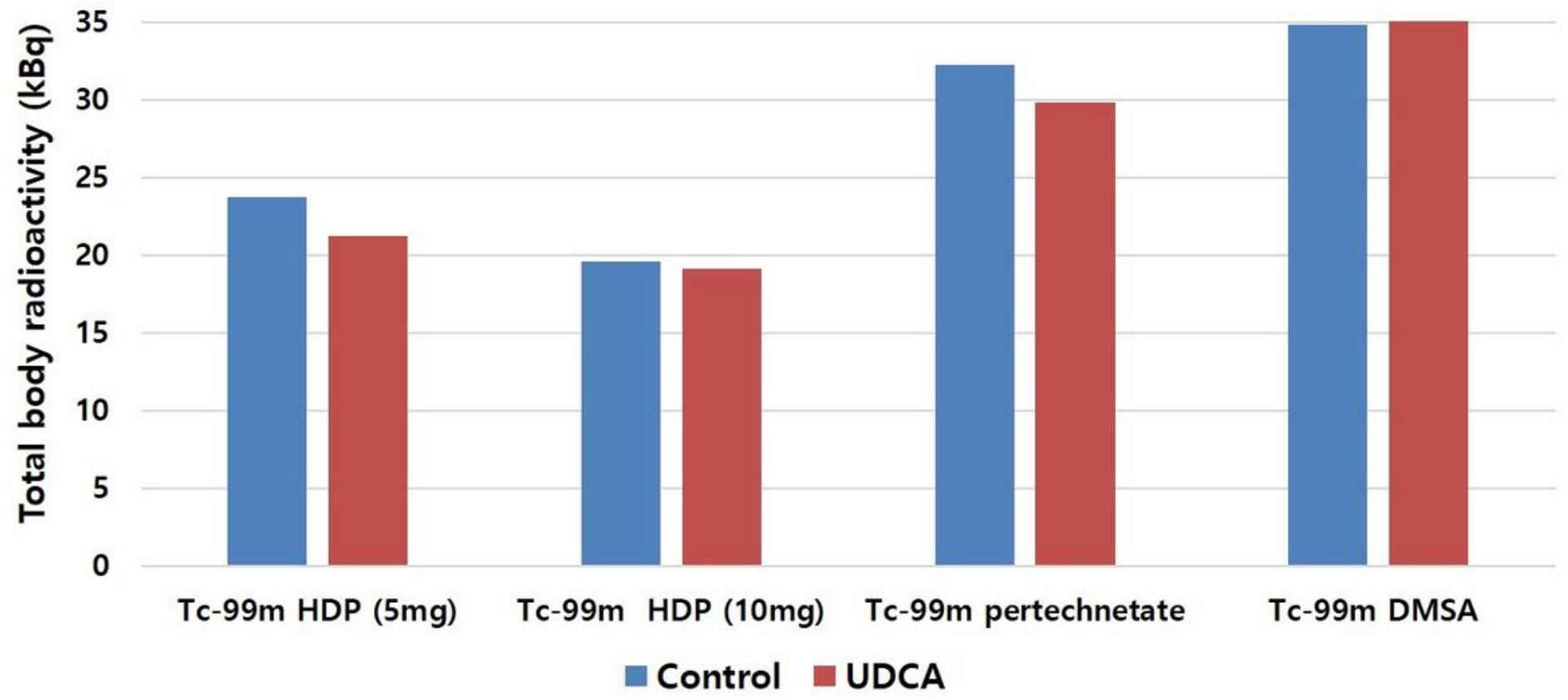

Figure 7

Total body radioactivity after all 5 image acquisition time points. Total body radioactivity was measured with a dose calibrator and was generally lower in the UDCA group, except for in the Tc-99m DMSA experiment. The difference between the 2 groups was not statistically significant. 


\section{Time Activity Curve of the Kidney using Tc-99m MAG}

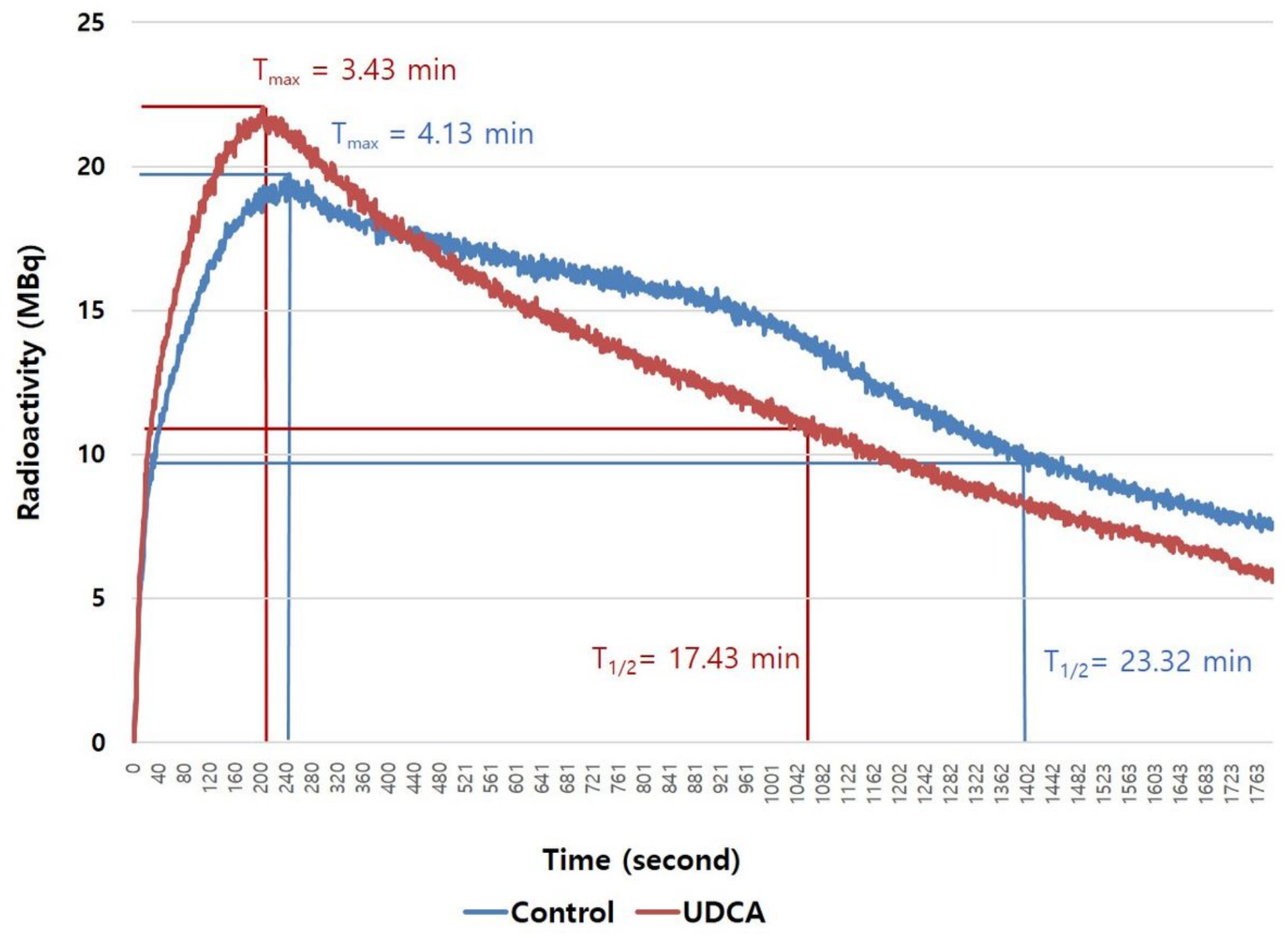

Figure 8

The time activity curve of the kidney from the 2 groups was compared. Time to peak renal activity (Tmax) and half-time of renal activity (T1/2) were shorter in the UDCA group (Tmax: $3.43 \mathrm{~min}, \mathrm{~T} 1 / 2: 17.43 \mathrm{~min}$ ) than in the Control group (Tmax: $4.13 \mathrm{~min}, \mathrm{~T} 1 / 2: 23.32 \mathrm{~min}$ ). 


\section{Time Activity Curve of the Kidney using Tc-99m MAG}

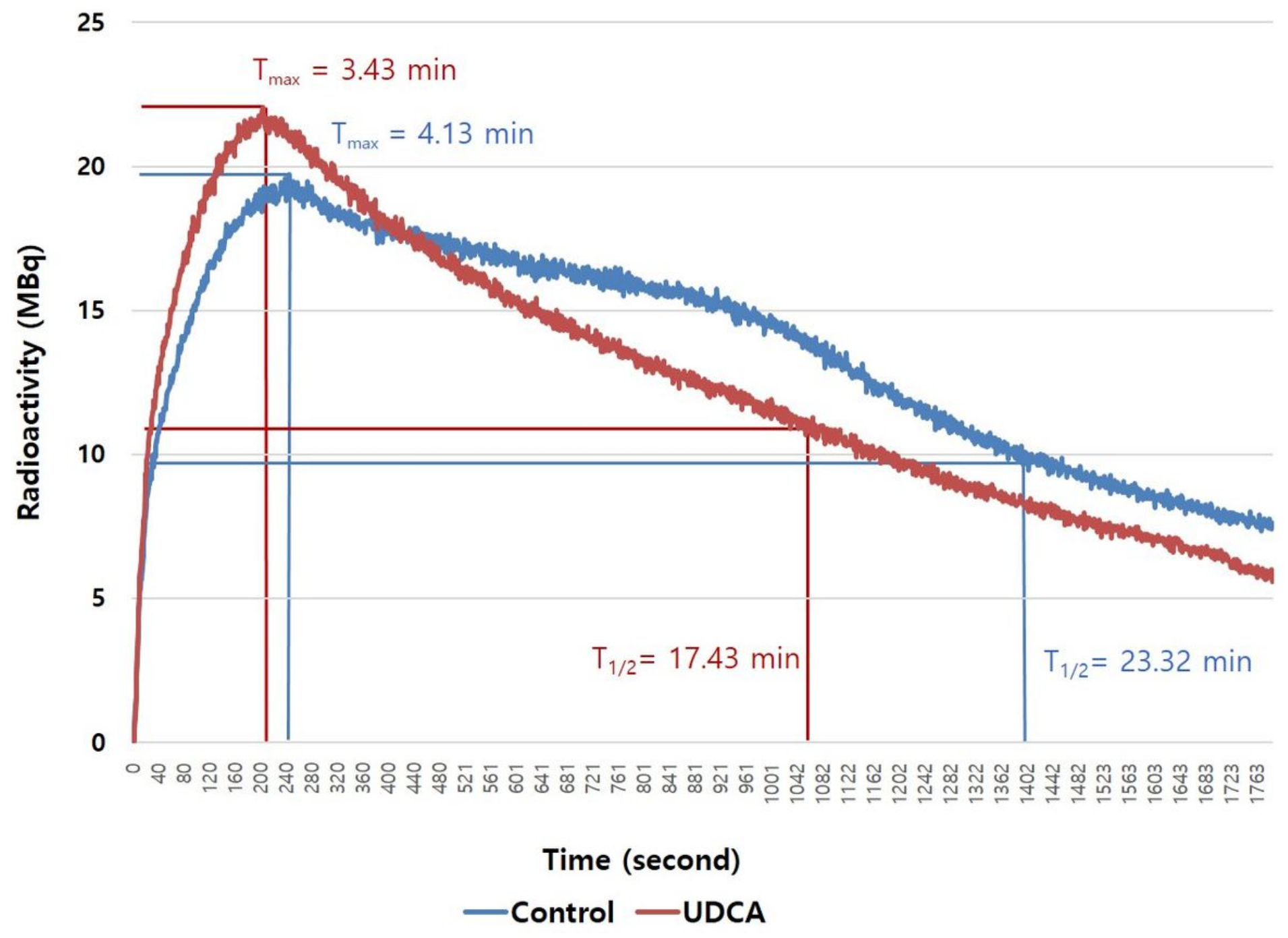

Figure 8

The time activity curve of the kidney from the 2 groups was compared. Time to peak renal activity (Tmax) and half-time of renal activity (T1/2) were shorter in the UDCA group (Tmax: $3.43 \mathrm{~min}, \mathrm{~T} 1 / 2: 17.43 \mathrm{~min}$ ) than in the Control group (Tmax: $4.13 \mathrm{~min}, \mathrm{~T} 1 / 2: 23.32 \mathrm{~min}$ ). 


\section{Time Activity Curve of the Kidney using Tc-99m MAG}

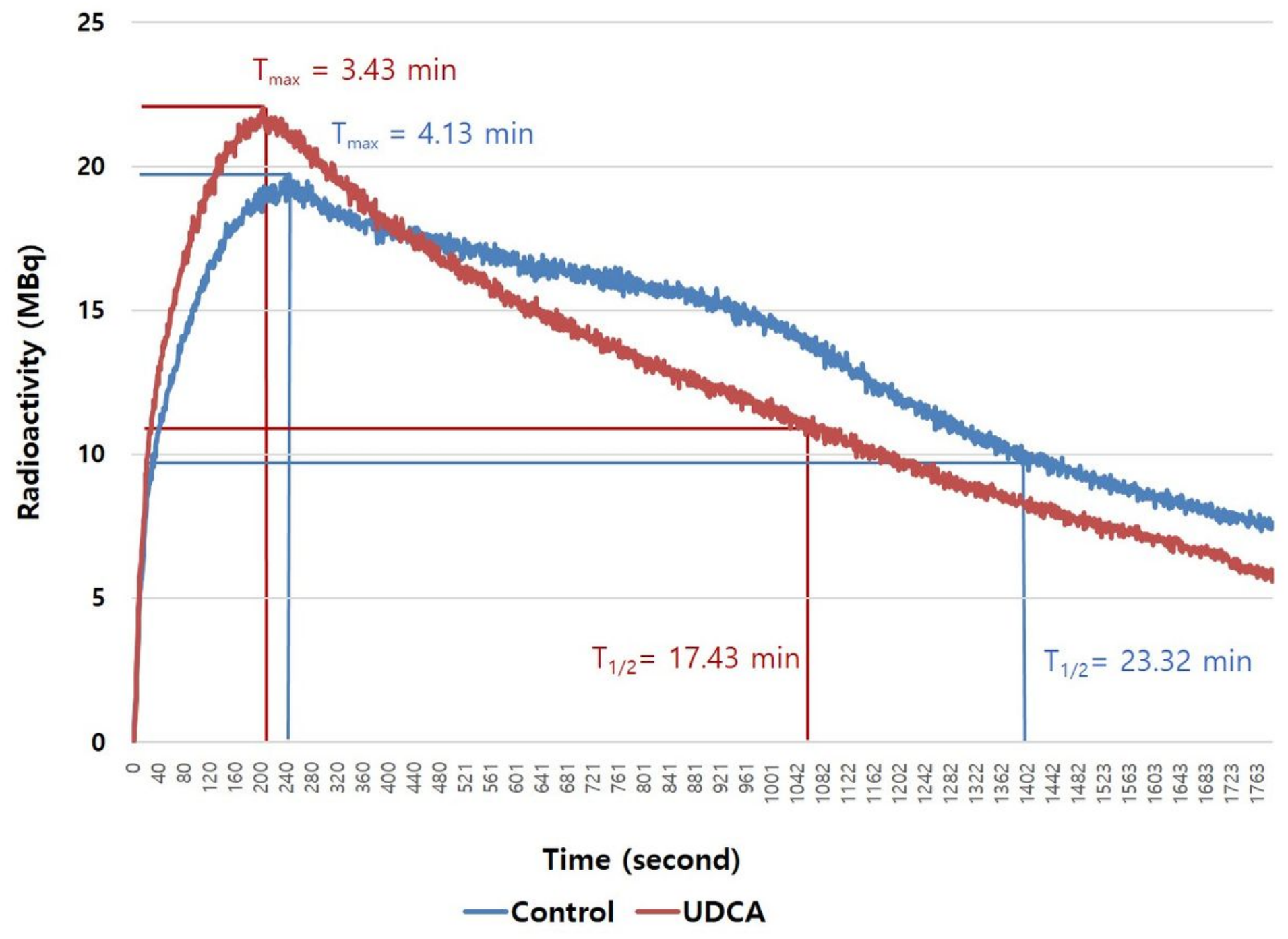

Figure 8

The time activity curve of the kidney from the 2 groups was compared. Time to peak renal activity (Tmax) and half-time of renal activity (T1/2) were shorter in the UDCA group (Tmax: $3.43 \mathrm{~min}, \mathrm{~T} 1 / 2: 17.43 \mathrm{~min}$ ) than in the Control group (Tmax: $4.13 \mathrm{~min}, \mathrm{~T} 1 / 2: 23.32 \mathrm{~min}$ ). 


\section{Radioactivity/Total body activity (\%) of Tc-99m MAG 3 Scan}

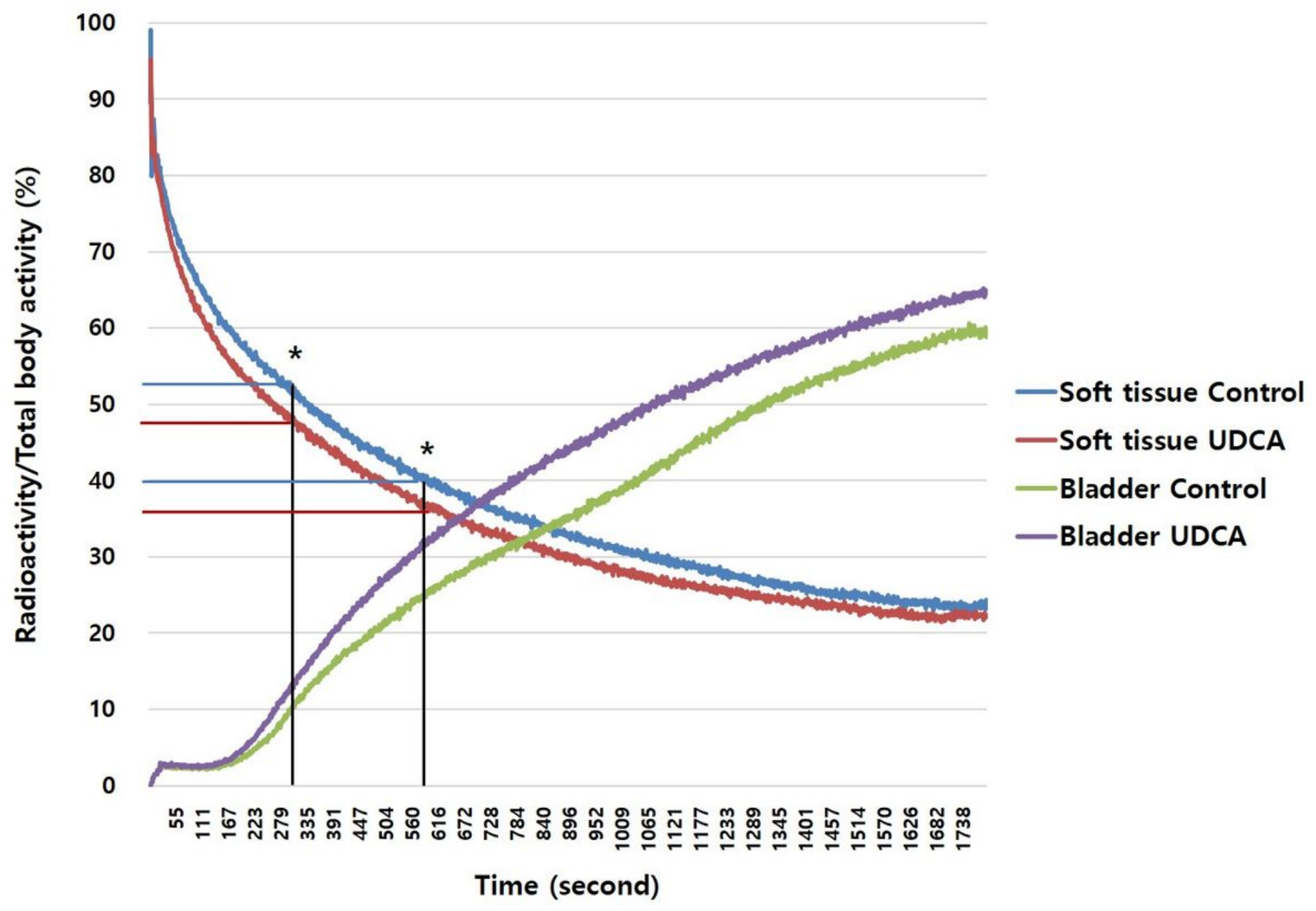

Figure 9

Radioactivity/TBA (\%) curves from the Tc-99m MAG3 scan show earlier excretion of radioactivity from the soft tissue in the UDCA group. An asterisk (*) indicates statistical significance. 


\section{Radioactivity/Total body activity (\%) of Tc-99m MAG 3 Scan}

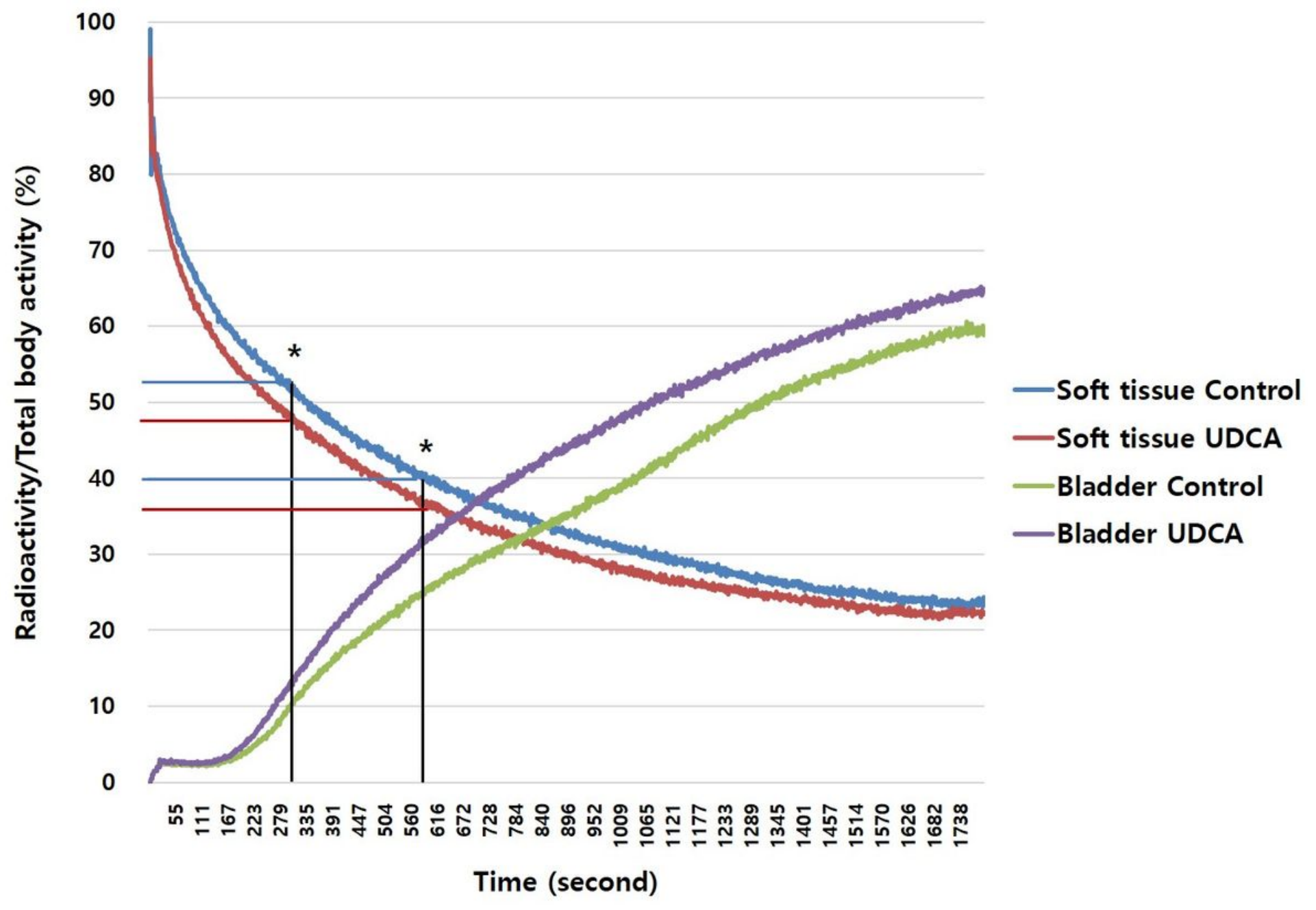

Figure 9

Radioactivity/TBA (\%) curves from the Tc-99m MAG3 scan show earlier excretion of radioactivity from the soft tissue in the UDCA group. An asterisk (*) indicates statistical significance. 


\section{Radioactivity/Total body activity (\%) of Tc-99m MAG 3 Scan}

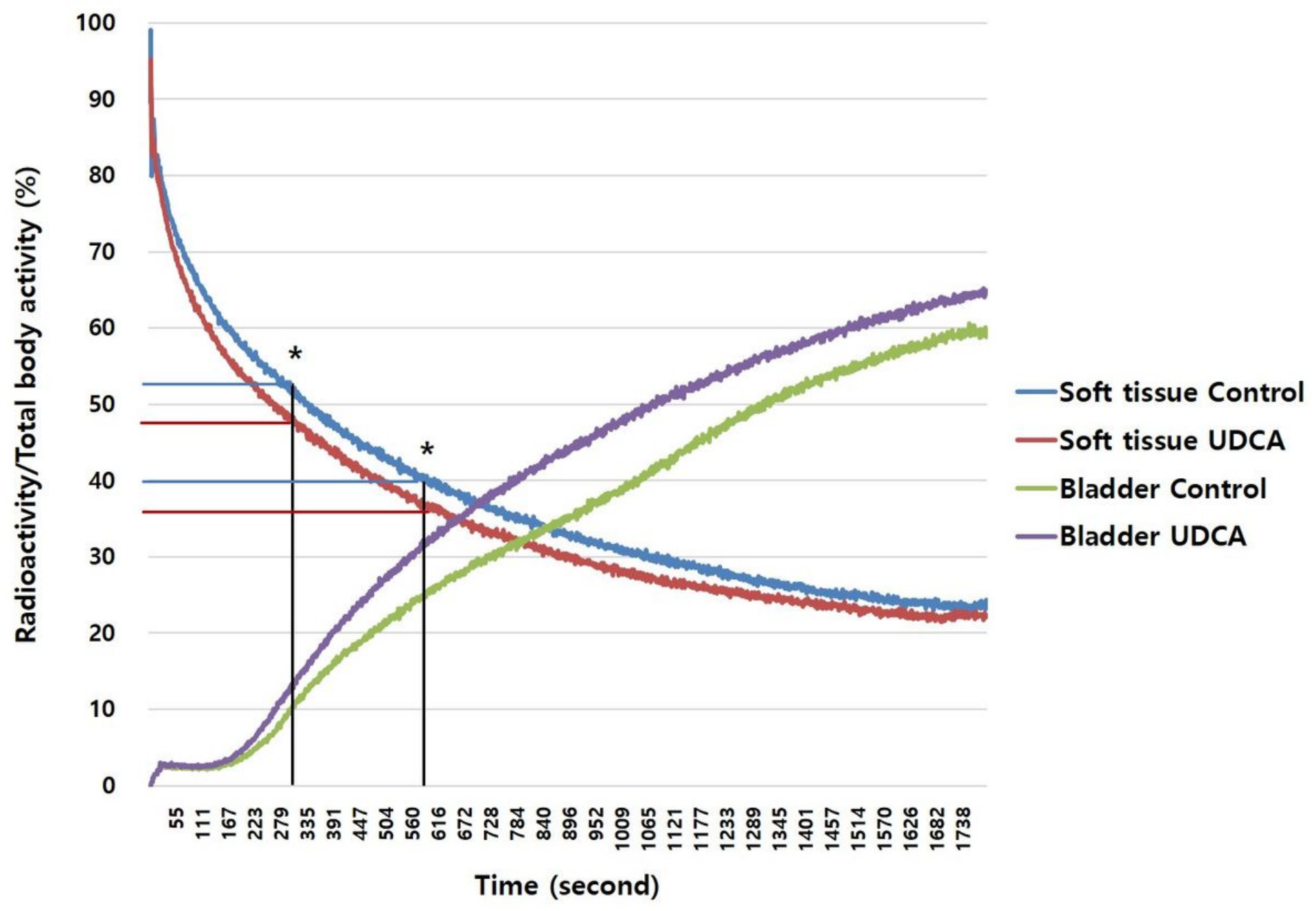

Figure 9

Radioactivity/TBA (\%) curves from the Tc-99m MAG3 scan show earlier excretion of radioactivity from the soft tissue in the UDCA group. An asterisk (*) indicates statistical significance. 